\title{
Chemical Kinetic and Combustion Characteristics of Transportation Fuels
}

\author{
Frederick L. Dryer \\ Department of Mechanical and Aerospace Engineering \\ Princeton University, Princeton, NJ 08544
}

Corresponding author:

Frederick L. Dryer

Department of Mechanical and Aerospace Engineering

Engineering Quad

Olden Street

Princeton, NJ 08540

fldryer@princeton.edu

Plenary Contribution

September 23, 2014

1

(C) 2014. This manuscript version is made available under the Elsevier user license 


\begin{abstract}
Internal combustion engines running on liquid fuels will remain the dominant prime movers for road and air transportation for decades, probably for most of this century. The world's appetite for liquid transportation fuels derived from petroleum and other fossil resources is already immense, will grow, will at some future time become economically unsustainable, and will become infeasible only in the very long term. The ongoing process of augmenting and eventually replacing petroleum-derived fuels with liquid alternative fuels must necessarily involve approaches that result in comparatively much lower net carbon cycle emissions from the transportation sector, most likely through a combination of carbon sequestration and renewable fuel production. The successful growth and establishment of a sustainable, profitable alternative fuels industry will be best facilitated by approaches that integrate alternative products into petroleum-derived fuel streams (i.e., gasolines, diesel, and jet fuels) and consider synergistic evolution of and integration with prevailing refining and liquid fuel distribution infrastructures.

The emergence of low temperature combustion strategies, particularly those implementing dual fuel methods to achieve Reaction Controlled Compression Ignition (RCCI), offers the potential to significantly improve operating efficiency and reduce emissions with minimal aftertreatment. For all advanced combustion engine technologies, but especially for RCCI, a clear understanding of fuel property influences on combustion behaviors will be important to achieving projected engine performance and emissions.

To achieve the benefits projected by emerging engine technologies, the properties of petroleumderived fuels themselves must be modified over time, but the effects of blending candidate alternative fuels with these conventional fuels must also be understood. Predicting the coupled physical and chemical property effects of real fuels on energy conversion system performance and emissions is a daunting problem, even for petroleum-derived real fuels, since each is composed of several hundred to thousands of individual chemical species typically belonging to one of a few organic classes (e.g., n-paraffins, isoparaffins, cyclo-paraffins, olefins, aromatics). For specific combustion applications, it is often the global combustion response to variations in the composition of fuel mixtures - inclusive of those occurring by blending petroleum-derived fuel with alternative fuel candidates - that is of interest for fuel property optimization. This paper presents an overview of tools used for evaluating and emulating combustionrelevant properties of real fuels and alternative fuel candidates. New analytical and statistical methods can provide important insights as to how the ensembles of distinct molecular structures found in a given fuel mixture contribute to the physical and chemical kinetic properties that govern its combustion in energy conversion processes. Such tools can in turn assist in screening candidate alternative fuels for more detailed study.
\end{abstract}




\section{Contents}

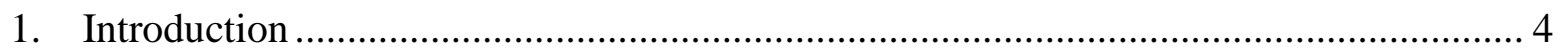

2. Characterizing Real Fuels for Engine Combustion Applications ............................... 7

2.1 Reference Indicators for Autoignition in Engines ............................................ 8

RON, MON, and homogeneous charge engine applications ..................................... 9

Cetane Indicators and Multi-phase Combustion ...................................................... 13

2.2 Sooting and Average Molecular Weight Indicators.......................................... 14

2.3 Advances in Chemical Analysis Methods ...................................................... 16

2.4 Multi-phase Combustion Modeling with Real Fuel Properties ............................ 17

3. Surrogate Mixture Concepts and Approaches for Emulating Real Fuel Combustion

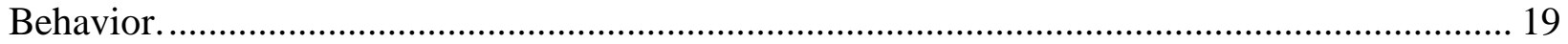

Some Comments on Selecting Surrogate Components and Testing Mixture Behaviors

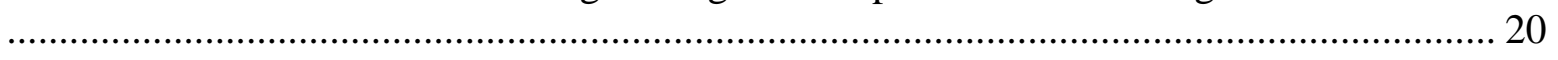

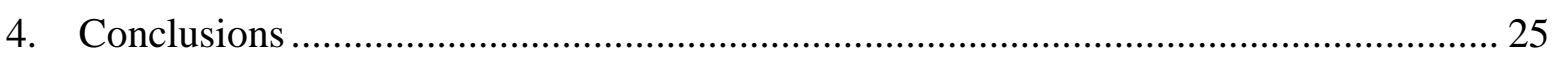

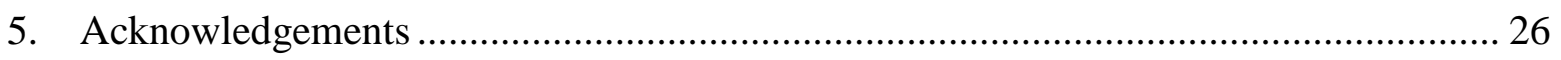

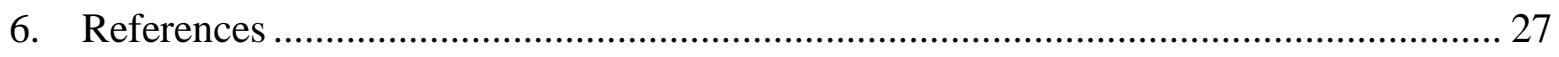




\section{Introduction}

In a novel Hottel Lecture at the $28^{\text {th }}$ Symposium [1], Prof. Glassman focused on the challenge that the internet revolution and globalization would likely pose to the existential purpose of the combustion community over the coming century. I echo here his cautionary dichotomy that while science is an "endless frontier" where research can be stimulated by a thirst for advancing knowledge of the world around us, discovering and unraveling its intricacies, and revealing its fundamental elegance, only by transferring fundamental discoveries to generate new products and services for the evolving market can true social and economic returns on investment in basic science be realized. Through the intervening years, I have observed that Prof. Glassman's perception endures: the ever-accelerating pace of information transfer and globalization has only intensified the need for transformative, close-coupled, use-inspired basic research and emphasized shorter time constants for technology transfer and implementation. And so I contend that a philosophy of use-inspired research is even more relevant today.

The discourse over the finiteness of fossil resources, and more recently the relevance of greenhouse and particulate pollutants to public health and climate change, has inspired an immense interest in basic science. On the distant horizon, such science may enable the "replacement" of fossil energy and define suitable frameworks to achieve a "sustainable" energy future by, e.g., deriving new candidate fuel molecular structures through bio-refining, solar fuel production, photochemical hydrogen production and carbon dioxide reduction, and developing hydrogen as an energy carrier. Certainly, the innovative nature of such high-risk/high-reward basic science pursuits might result in game changing impacts that would be extremely valuable in shaping longer term planning and product development in the far future. Improving energy efficiency, reducing net carbon emissions, and/or providing "energy security" have been amongst the more frequently proclaimed motivators for these basic science efforts.

However, impact from these application-motivated basic science endeavors is needed in the near term. We therefore must carefully consider how we can best transform to the new, longterm visions, even as we must conform to a trajectory compatible with, and certainly constrained by, world politics and economics. Particularly in the transportation energy field, the interface of fundamental science and applied engineering must align with the essential realities imposed by the sheer size and complexity (one might call it the inertial character) of a socio-technical system with globally-linked infrastructure that has been shaped in large measure around fossil energy and in particular, petroleum. For over a century, transportation fuels, their production/supply infrastructure, and the evolving engine technologies that use them have been almost exclusively intertwined with petroleum and advances in petroleum refining technology.

It is interesting to compare the vision of engine and fuel evolution of 1981 [2] to the vision for transportation today [3]. Certainly, the introduction of other energy resources based upon the prospect of crossing the peak of petroleum production was foreseen even then, but today's consensus trajectory puts much higher emphasis on emissions and thermal efficiency, and also emphasizes methodologies to reduce net carbon emissions [3] while avoiding pressure on biodiversity, counterproductive land use, and greenhouse gas emissions impacts [4]. Today's trajectory represents an amalgam of often disparate, complex national and global systems problems that impact humankind's ability to achieve improved living standards, mitigate pollution and climate change, and prepare for a very different long term energy future.

The dynamics of real engines, integration of electronics, sensor technologies, real time control, and the operating constraints imposed by environmental impacts continue to drive revolutionary advances in internal combustion engine technologies, with their eventual 
deployment constrained only by market economics and social acceptance. Recent advances for ground transportation applications have such potential to significantly improve energy utilization, efficiency, and reduce emissions that they represent ever more challenging targets of merit for alternative energy conversion options (e.g., electric, fuel cell). Projections clearly say that combustion and liquid transportation fuels will still dominate transportation for the next 50 years, and much longer [5-8], with fuels mainly produced from fossil resources [9-12]. The volume of legacy vehicles forces fuel evolution to consider both advancing and existing engine technologies, as well as integration with the current production and supply infrastructure. Carbon sequestration technologies, e.g. [13], cannot be avoided if we wish to address carbon pollution.

At present, there are only two renewable alternative fuels that are widely used for transportation: ethanol [14], and biodiesel [15, 16]. But, neither ethanol nor biodiesel can be distributed through pipeline systems handling petroleum product distribution (e.g., [17]). And we need to understand more completely the use of ethanol on tropospheric ozone levels through gathering of actual data [18]. Cellulosic and algal renewable fuels will need to emerge with sufficient economic advantage to accelerate alternative fuel usage, and in a manner that better addresses fuel distribution and storage. One way to address the latter is to produce alternative feed stocks that are composed of fully hydrogenated species similar to those found in petroleum derived fuels $[17,19]$. Upgrading will require additional hydrogen, and methods for generating hydrogen without increasing carbon emissions are critical needs for the future.

Non-oxygenated fuel feedstocks that are entirely compatible with petroleum have distinct advantages in terms of product refining, distribution, storage, and global fit-for-purpose certification. The strategic, international, and safety aspects associated with air transportation provide an example through extensive efforts to introduce non-oxygenated "drop-in" alternative fuels [20]. These fuels are typically fully hydrogenated paraffinic mixtures, containing few if any aromatics or contaminants such as sulfur, metals, etc. Blending of these stocks with today's jet fuels is beneficial as a means of reducing ground and upper atmospheric particulate mass emissions associated with sulfur and aromatic content [21, 22]. Even here, blending is constrained by legacy aircraft compatibility [23]. There are indications that petroleum products themselves could today be processed to achieve similar reductions in sulfur and aromatics at costs competitive with alternative jet fuel blending, suggesting that the advantages of renewable jet fuels are the potential for augmenting petroleum products and decreasing net carbon cycle emissions [24]. Though argued that aircraft applications are better purposed [25], the high cetane number of many of these materials is also conducive to diesel applications without strong blending limit constraints [17]. Hydrotreated renewable diesel derived from algae is also under consideration by the U.S. Navy [26-28]. Non-aromatic alternative fuels with cetane numbers ranging from 30 to 70 or more (see later discussions) can be produced by varying the ratio of normal and iso-paraffinic fractions.

A plethora of oxygenated species have emerged as potential ground transportation fuels/fuel components [29]. In addition to extensive research on alcohols [14] and their blends with petroleum (e.g., [30-32]), other types of oxygenated structures such as ethers [33, 34], carbonate esters [35, 36] valerates [37, 38], ketones [39], furans [40-46], acetates [47, 48] and oxygenate mixtures of acetone-butanol-ethanol $(\mathrm{ABE})[49,50]$ have all received interest in the last few years as ground transportation fuel candidates, driven by their use as extenders for fossil fuels, in blends with fossil fuels to reduce emissions or increase octane number, and, more recently, for potentially lower processing and refining losses (through bio-refining methods). 
But the implementation and scale up of any candidate requires assessments of health [41], ground water contamination, biochemical/thermal stability [23], physical properties, blending compatibility with petroleum products [37, 51, 52], fuel system materials compatibility, and environmental reactivity [53]. Given past controversies in the United States over methyl tertbutyl ether (MTBE) [http://www.epa.gov/mtbe/] as a gasoline additive, it appears prudent to consider these matters prior to investing significantly in detailed fundamental and applied combustion research or production scale-up economics. Some have suggested that the least complicated option to fuel integration may be hydrotreated alternative "crudes" [54] that can be co-refined with petroleum. The advantage is that finished fuel properties and regulatory issues would then be universally managed (regulated) at the refinery gate, retaining the flexibility to evolve fuel properties as engine technologies and fleet requirements change. Combustion advantages of oxygenate addition to emissions mitigation needs to be carefully assessed in terms of advancing engine technologies.

The energy industry currently forecasts that the production ratio of distillate/gasoline fuels of today's refineries will need to increase significantly in the future, based upon a predicted increase in diesel use over gasoline fueled systems $[55,56])$. On the other hand, innovative dual fueled engine technologies with "intelligent" engine control systems that can optimize autoignition quality and burning rate timing of the air/fuel charge by real time mixing of high cetane (diesel-like) and high octane (gasoline-like) fuels (Reactivity Controlled Compression Ignition - RCCI operation) are emerging that have potential to achieve much higher efficiencies than highly boosted advanced gasoline or diesel concepts [57, 58]. These approaches typically utilize large amounts of gasoline-like (high octane, "low reactivity") fuels to be co-used with diesel-like (high cetane, "high reactivity") fuels on board the vehicle. Maintaining modified gasoline/diesel distribution to meet legacy and advancing gasoline [59], diesel, and dual fuel technologies will be challenging [60].

Irrespective of the future directions, advances in efficient and predictive methods to incorporate fuel properties into computational engine design tools that replicate appropriate kinetic, molecular transport, and turbulence/chemistry coupling effects are needed today for facilitating engine and fuel technology engineering design, e.g., see [58]. The computational combustion modeling field has made incredible advances since the $50^{\text {th }}$ Anniversary review of Endeavors in the sciences are making excellent contributions to developing more quantitative fundamental descriptions for atomization [61, 62], detailed chemical kinetics [14, 38, 63, 64], transport properties, and turbulence/chemistry interactions and also in advancing methods to produce dimensionally reduced kinetics and to otherwise speed computations. The "Moore's Law" characterization of progression in computer speeds, memory, and architecture [65] enabling fundamentally based engineering design "on paper" continues to be constrained by the levels of approximations that must be made in order to accommodate parametric computations. Well considered computational modeling approximations, optimized and validated to reproduce complex experimental observations, remain essential for producing computational engineering design and development tools, for interpreting applications-oriented basic research results on even single component and binary fuel mixtures, (e.g. see [66, 67]).

But every real petroleum-derived and hydrotreated alternative liquid fuel for gasoline, diesel and jet applications is composed of several hundred to a thousand or more unique species, distributed among organic classes (the typically referred five are; n-paraffins, iso-paraffins, cyclo-paraffins, olefins and aromatics), Figures 1, 2. In the face of new engine technologies and emerging fuels not derived from petroleum, we need to understand how best to integrate the new 
fuel components into the changes that will occur in the market dominated by petroleum products. The remainder of this paper will discuss progress on some of the constraints and approximations to be considered in emulating the wide range of real fuel physical and chemical kinetic properties influencing applied combustion behaviors that relate to the need for this integration. Applications of chemical structural and molecular analysis measurements and statistical methods for characterizing real fuels, their molecular components, and their functional group composition are providing important scientific insights, evolving improved methods to model the physical and chemical kinetic properties that affect combustion, and to design future fuels [68]. Many of these approaches can already be applied to screen candidate alternative fuel species for more detailed study and to assure compatibility in integrating them with use in a liquid fuel transportation market based upon fossil (especially petroleum) derived fuels. But first it is important to briefly review how the properties of real fuels are characterized.

\section{Characterizing Real Fuels for Engine Combustion Applications}

Fit-for-purpose fuel standard specifications are applied to assure that commercially available fuels will achieve engine performance and emissions commensurate with the manufacturer's specifications, while real "certification fuels" are typically developed for "qualifying" engine performance and emissions over representative operating scenarios. Worldwide, fuel specification standards vary by nation and region, with many adopting and/or cross-referencing with those of ASTM International [69] or the European Committee for Standardization (CEN) [70]. These fuel specification standards must allow for some variability in finished fuel properties in order to accommodate differences in petroleum crudes and fuel processing. Engines must be designed to accept these fuel tolerances. As a result, the organic class distribution of fuels that have been determined to be "fit-for-purpose" can vary considerably as should be inferred from Figures 1, 2.

The compositional complexity of alternative fuels and components, as well as their blends with petroleum derived fuels can produce chemical and physical properties that frequently lie outside the historical experience envelope based on petroleum products. Hence, standards criteria and testing for fit-for-purpose verification must evolve in response to the introduction of new fuel components, as exemplified in recent updates for jet fuels [20]. Similar revisions are to be expected for incorporating new classes of oxygenated as well as hydrotreated alternative fuel components into ground transportation fuels. Developing revised standards typically requires considerable and expensive full-scale engine/fuel verification tests.

Due to the lack of a quantitative fundamental understanding of the complicated multichemico-physical-fluid dynamic interactions that affect engine combustion, engineering reference indicators developed nearly a century ago remain central to characterizing real fuels. Fit-for-purpose standards specify range limits for select chemical properties - element and species contents (hydrogen, benzene, sulfur, lead, oxygen content or specific oxygenates, etc.), organic class fractions (aromatics, olefinics, naphthalenes), gum content, ash, select "chemical" reference indicators (e.g. Research Octane Number $(R O N)$, Motor Octane Number $(M O N)$, Cetane Number $(C N)$, heat of combustion, smoke point $(S P)$, etc.), and select "physical" reference indicators (e.g. density, distillation curve parameters, flash point, reference viscosity, fluidity (freezing point), cloud point, thermal stability, lubricity, corrosion, volatility, etc.), depending on the intended fuel type (gasoline, diesel, gas turbine). Each parameter can be determined directly by one or more approved experimental test procedures or by correlations 
among measured parameters, for example, the cetane index $(C I)$ [71]. Alternative fuels and their blends with petroleum based fuels may not fall within the petroleum history represented by these correlations [72].

Engine/fuel interactions for a specific IC engine are typically expressed in terms of application target data (for example, autoignition, burning rates, cylinder pressure history, preignition, engine knock, super knock, specific fuel consumption, emissions, etc. for piston engines [60]); flash back, flame volume, flame stability, radiative loading, lean blow-out, re-light, emissions, etc. for gas turbines) that relate to specific engine design/operating conditions and fuel chemical/physical reference indicators. For example, engine knock and super knock in advanced spark ignition piston engines were discussed in terms of relationships to RON, MON, and their difference in another plenary at this symposium [60]. These and other relationships are developed through experimental testing, supported by theoretical interpretation and numerical modeling and remain central to interpreting fuel effects on applications targets. The more important of these are the autoignition indicators $(R O N, M O N, C N)$; the sooting indicator, smoke point $(S P)$; and indicators for the distillation curve. While species class composition distribution over the distillation curve remains unspecified, chemical analytical tools have sufficiently advanced in the past ten years to much better characterize such detailed features.

What follows are some brief discussions on important reference indicators for relating fuel properties to both fundamental and applied research.

\subsection{Reference Indicators for Autoignition in Engines}

Reference spark ignition indicators (RON/MON) ASTM D2699/ASTM D2700 or the compression ignition indicator $(C N)$ are historically based upon single cylinder engine tests and are ingrained quantities in developing the interface of fuel with engine requirements (indicated by major heat release in the cylinder charge end gas). This interface is replicated under conditions representing different pressure/temperature time histories for $R O N$ and $M O N$ defined by the engine RPM (600 and 900 RPM) and intake temperature (52 and $149 \mathrm{C}$ ), respectively. RON/MON are determined for the volume fraction of iso-octane in a primary reference fuel $(\mathrm{PRF})$ mixture of iso-octane $(O N=100)$ and $\mathrm{n}$-heptane $(O N=0)$ that reproduces the same "autoignition characteristic time" and "knock intensity" as observed for a given test fuel. The autoignition event in the unburned gases is dependent upon chemical reactions in the end gas and subsequently some heat release occurring during the compression pressure/temperature history imposed by the piston motion and the spark initiated turbulent burning propagation through the premixed charge.

On the other hand, $C N$, is determined by comparing autoignition events for a fuel and a reference mixture of heptamethyl-nonane $(C N=15)$ and n-cetane $(C N=100)$ under the same liquid fuel injection timing into the engine cylinder. This phenomenon involves liquid fuel atomization, vaporization, and mixing, and eventual autoignition in mixing regions where local equivalence ratios significantly depart from the average value of the cylinder charge. The observed autoignition event thus results from coupled physical and chemical kinetic controlled phenomena, dependent on the properties of both the reference and real fuels.

Engine tests are laborious and require considerable fuel sample volumes. In the last decade, Derived Cetane Number $(D C N)$ methods have emerged that require only small sample volumes of the test fuel. The tests interpret an "ignition delay time" for the initiation of liquid fuel injection into a fixed volume of heated, high pressure air to an observed pressure rise (heat 
release), correlated in reference measurements from engine test results. Statistical averaging from repeated injections that typically differ by as much as six $D C N$ numbers result in very repeatable $D C N$ test averages. However, the different commercial configurations sometimes result in conflicting $D C N$ results outside their individually stated uncertainties [73]. Moreover, the numbers can sometimes differ from $C N$ values.

Large databases for cetane and octane numbers for individual molecular species and test fuels have accrued over time. Numerous correlations of such data are available. Those of Ghosh et al. $[74,75]$ are particularly interesting in that the limiting case of individual pure component predictions, as well as for their mixtures, and some common oxygenate components are all considered. Non-linear blending and addition of new species can be encompassed straightforwardly, including emerging oxygenated fuel candidates [76]. The merits of blending rules based upon molar and liquid volume have been compared [77, 78] in terms of their predictive uncertainties, though it appears that any distinction is mostly dependent on the interpretive manner in which the correlating methodologies are applied [79].

Based upon difference in derivation methodologies and conditions, it is surprising that quantitatively accurate property-property relationships for octane and cetane indicators exist. The relationships are sufficiently accurate that $D C N$ measurements can be converted to $M O N$ and RON [80]. DCN measurements on new alternative fuel candidates [76] can indicate which fuel pool (gasoline or diesel) is most appropriate and provide data for determining their blending behaviors with petroleum derived fuels [81].

Below, each of these autoignition reference indicators and their relationship to engine operational modes are briefly discussed.

\section{RON, MON, and homogeneous charge engine applications}

As noted by Kalghatgi [60], the effects of gasolines on homogeneous charge engine combustion are related to RON and MON through the Octane Index, OI, defined as

$$
O I=R O N-K(R O N-M O N)
$$

The difference $R O N-M O N$ is referred to as the Octane Sensitivity, $S$, and $K$ is a constant, dependent of the evolution history of $\mathrm{P}$ and $\mathrm{T}$ in the unburned gas, i.e. a function of the engine operating condition. The value of $K$ (assumed to be independent of fuel) can be arrived at through various approximations, but there are no fundamental theories from which $K$ can be derived. The discussions in [60] touch upon $R O N, M O N$, and $O I$ in relation to spark ignition engines, and (in more general terms) discuss their adaptation to HCCI/RCCI applications. The relevance to $\mathrm{HCCI} / \mathrm{RCCI}$ applications is addressed further here, as there are continuing concerns that alternative indicators may be needed to characterize fuels for this application.

The key to HCCI/RCCI engine operations is the appropriate timing of heat release in the engine cycle, frequently characterized as the crank angle when $50 \%$ of the total heat release available from the charge occurs, CA50, before or after the top dead center piston reference crank angle. Both the combustion timing and combustion phasing (shape) of the heat release profile are important to optimizing HCCI operation power output as a function of load, as well as thermal efficiency, emissions, and stability [82]. The autoignition timing and heat release profiles for different primary reference fuel (PRF) mixtures and a specified set of engine 
operating conditions was recently studied experimentally and numerically [83], examples of the experimental observations are shown in Figure 3.

The rate of heat release $(R O H R)$ is observed to be a complex function of the multi-stage kinetic behavior of the fuel air mixture; a low temperature heat release $(L T H R)$ region, a high temperature heat release region $(H T H R)$ where the major heat release occurs, and a transition region of intermediate temperature heat release (ITHR) which is often more difficult to identify. In the referenced experiments, iso-octane (PRF-100) displayed no LTHR, but increasing ITHR over the intake pressure range studied (1.0-1.6 bar). LTHR behavior first appeared with PRFs between 95 and 85 with onset pressure for $L T H R$ decreasing with decreasing PRFs. Significant increases in ITHR occurred with increased $L T H R$, both heat release rates increasing with increasing equivalence ratio. LTHR kinetics are a significant contributor to ITHR activity in terms of the radical pool produced as well as heat release, and both LTHR and ITHR contribute to advancing the crank angle location for HTHR.

Figure 4 summarizes the general types of chemical kinetics associated with the reactivity of PRF mixtures, the addition of toluene to PRF-87, and pure toluene as observed in the Princeton Variable Pressure Flow Reactor (VPFR) [84, 85]. Figure 4 displays the reactivity profiles for carbon oxidation associated with destruction of the carbon containing species, as water is formed throughout the entire range of reactivity, principally by reactions of the hydroxyl radical, $\mathrm{OH}$. Conversion of carbon monoxide to carbon dioxide is significantly suppressed by competition of hydrocarbon species and fragments with $\mathrm{CO}$ for $\mathrm{OH}$, and thus the oxidation of $\mathrm{CO}$ is a principal contributor to HTHR.

Detailed modeling described in [85] as well as that presented in [83] show that LTHR is associated with oxidation controlled by molecular oxygen addition to radicals produced by $\mathrm{H}$ atom abstraction from fuel species, primarily by $\mathrm{OH}$ and hydroperoxyl $\left(\mathrm{HO}_{2}\right)$ radicals. Degenerate branching results from subsequent reactions of $\mathrm{O}_{2} \mathrm{QOOH}$ formed by $\mathrm{QOOH}+\mathrm{O}_{2}$. As temperature increases, the molecular oxygen addition reactions $\mathrm{R}+\mathrm{O}_{2}$ and $\mathrm{QOOH}+\mathrm{O}_{2}$ slow as the equilibrium constants for these reactions shift toward reactants, reducing degenerate branching and producing the observed negative temperature coefficient (NTC) kinetic behavior.

Note that the observed oxidation (and the associated LTHR) is largest for n-heptane $(\mathrm{PRF}=0)$ in Figure 4, with no low temperature oxidation exhibited for iso-octane (PRF-100) or toluene. Toluene addition to PRF 87 competes with the PRF species for reactive radicals, principally $\mathrm{OH}$ and $\mathrm{HO}_{2}$. The intermediates that result from the abstraction reactions with toluene regenerate $\mathrm{OH}$ and $\mathrm{HO}_{2}$ radicals much more slowly than those intermediates formed from $\mathrm{OH}$ or $\mathrm{HO}_{2}$ reactions with n-heptane or iso-octane, thus suppressing the net overall reactive radical pool of the mixture. Similarly, it is the competition of iso-octane for radicals produced from n-heptane that suppresses the radical pool for oxidation of PRF mixtures relative to that found for pure n-heptane oxidation.

The NTC behavior is terminated by "hot ignition" (Figure 4), as a result of reaching conditions where hydrogen peroxide $\left(\mathrm{H}_{2} \mathrm{O}_{2}\right)$ formed in the oxidation rapidly decomposes to yield $\mathrm{OH}$ radicals [86, 87]. Subsequently, degenerate branching occurs primarily through $\mathrm{HO}_{2}$ reactions with hydrogen-containing species to produce $\mathrm{H}_{2} \mathrm{O}_{2}$, followed by $\mathrm{H}_{2} \mathrm{O}_{2}$ decomposition. As temperatures continue to increase, beta scission reactions of larger alkyl radicals and oxygenated intermediates produce smaller reactive fragments that subsequently lead to $\mathrm{HO}_{2}$ formation and further acceleration of the overall rate of reaction and accompanying heat release rate. Collectively these reaction paths are responsible for ITHR. The heat added to the reacting system through the combination of LTHR and ITHR subsequently lead to HTHR, associated 
primarily with the oxidation of carbon monoxide by hydroxyl radicals. As noted earlier, carbon monoxide oxidation is significantly inhibited by the competition of hydrocarbon species for hydroxyl radicals.

Recently, Rapp et al. [88] compared the compression ratios for achieving the same CA50 for a number of PRF mixtures and several gasolines spanning a range of $R O N$ and $O I$. The base gasolines and PRF-70 were also blended with ethanol and methylcyclohexane to investigate oxygenate effects. The general conclusions of this work were that $O I$ and another recommended reference indicator derived for HCCI applications, the HCCI Index [89], correlated well the autoignition properties in their experimental studies for PRF mixtures, but not for real gasolines or for the effects of the additives. Moreover, their studies showed that for fuels or conditions requiring compression ratios higher than 15 for engine operation, no evidence of $L T H R$ could be inferred. Thus, the work concluded that new reference indices were needed for HCCI applications. In follow-on work [90] on ethanol/n-heptane mixtures, the blending of heptane to pure ethanol induced a dramatic increase in $I T H R$, with larger additions eventually causing LTHR. In qualitative agreement with earlier work that suggested $\mathrm{CH}_{2} \mathrm{O}$ chemiluminescence was a good marker for LTHR and ITHR [91], modeling calculations suggested that formaldehyde itself would be a good marker for ITHR. This suggestion is consistent with VPFR reactivities for large carbon number alkanes discussed later in this paper (Figure 10).

Conclusions derived in the recent work of Pera and Knop [92] on methodologies to construct surrogate mixtures for emulating fully prevaporized real gasolines in compression autoignition mode are at odds with the work of Rapp et al. [88]. They point out that PRFs really cannot match chemical properties of real gasolines other than to empirically approximate RON/MON sensitivity.

In our earlier work [85], as referenced in [93], it was pointed out that Gasoline H/C molar ratios vary considerably by source (though typically the order of 1.986 or less), even though they may share the same RON and MON. The H/C molar ratio for PRF mixtures must lie between 2.250 and 2.286 while those of real gasolines are on the order of 1.8, directly affecting even flame temperatures as a function of equivalence ratio [94]. Other related effects include, Zeldovich $\mathrm{NO}_{\mathrm{x}}$ formation rate, mass transport issues through the definition of the local air/fuel stoichiometry in stratified applications, and overall air/fuel flow rates related to turbulence levels within the combustion cylinder.

In our research, toluene $\left(\mathrm{C}_{6} \mathrm{H}_{5} \mathrm{CH}_{3}\right)$ was added the primary reference fuel baseline with the intent of matching gasoline: $\mathrm{H} / \mathrm{C}$ molar ratio, homogeneous reactivity as evidenced in the VPFR (e.g., see Figure 4), laminar flame burning rate, and flame temperatures. As observed in Figure 4, toluene itself exhibits no low temperature behavior and inhibits the low temperature and hot ignition behavior of PRF mixtures by competing for their active radical pool. These inhibiting characteristics affect both $L T H R$ and ITHR in comparison to those of PRF mixtures with similar RON and MON.

Pera and Knop chose the following property targets upon which to base a surrogate PRF plus toluene composition, to which other species were added to refine the composition to have closer target values to those of gasolines:

1. $\mathrm{H} / \mathrm{C}$ ratio, also noting the importance of this target to emissions, lower heating value, and density.

2. For oxygenated fuels the $\mathrm{O} / \mathrm{C}$ ratio was used as a target.

3. The molecular weight, $M W$, of the mixture.

4. The $R O N$ of the mixture.

5. The $M O N$ of the mixture. 
Correlations available in the literature for mixture $R O N$ and $M O N$ values $[74,95]$ were compared with their own data correlation used in defining the surrogate formulations.

Surrogates were formulated to represent a certification gasoline, ULG95. A PRF plus toluene surrogate mixture, Sur95t, was formulated first to represent $R O N$ and MON for the real fuel and H/C, followed by addition of ethanol to include the O/C content of ULG95 in the formulation, Sur95o, and finally the addition of cyclohexane and cyclohexene to the Sur95o to form another surrogate, Sur95f, which more closely matched the RON, MON, H/C ratio, O/C ratio, $M W_{\text {ave }}$, liquid density at $298 \mathrm{~K}$, and lower heating value of ULG95. The three surrogates and the ULG95 target gasoline were experimentally compared under the same controlled autoignition (CAI) combustion mode engine conditions with port fuel injection and negative valve overlap.

The Sur95t surrogate not only behaved similarly to ULG95 in terms of autoignition and CA50, but the power output and engine emissions for ULG95 were also recovered. The inclusion of the additional surrogate components in Sur95o and Sur95f led to closer replication of all noted ULG95 properties and progressively closer emulation of its experimental engine combustion behaviors. Finally, computational results compared favorably with the ULG95 engine data. A computational comparison of ULG95 experimental data and predictions using the Sur95t composition and detailed kinetic model were also performed using previously existing engine codes to analyze results using existing kinetic model components for Sur95t.

These findings and those of Rapp et al. [88] suggest that using the OI or the HCCI index to analyze HCCI operation on real gasolines lead to erroneous representation of real gasoline behaviors unless other reference indicators are also considered. It appears that, at the very least, $\mathrm{H} / \mathrm{C}$ and $\mathrm{O} / \mathrm{C}$ should also be the same as the gasoline target if appropriate kinetically related and scaling behaviors of $L T H R, I T H R$, and $H T H R$ are to be achieved. Homogeneous global combustion properties for petroleum derived gasoline can be replicated with simple mixtures of PRF and toluene, giving a base model to which alternative fuel component additions can be easily characterized. The results of progressively adding surrogate components to further refine the comparisons also provide opportunities for developing more compact models for engineering design applications that include blending effects of alternative components. Others have added different hydrocarbon components to emulate real gasolines [96]. It is likely, but could be easily established experimentally, that various other components can be used as well, if the surrogate component choices continue to reproduce the property target ranges represented by the real fuel.

In summary of this discussion, the inadequacies of using PRFs to emulate all of the above property targets is responsible for their failure to properly represent real gasoline behaviors in engines or in fundamental research experiments, as is concluded in another paper at this symposium [97]. A simple mixture of PRF components and toluene continues to be sufficient for experimentally evaluating the effects of additional components on gasoline global combustion and perhaps even emissions properties. Fundamental kinetic studies on PRF components and their interactions with other components in mixtures are important to kinetic model development and testing. Finally, dual fuel RCCI operation will likely introduce additional complexities resulting from techniques to stratify the charge prior to and even during the combustion event by the mode and frequency of fuel addition. 


\section{Cetane Indicators and Multi-phase Combustion}

That the cetane number reference indicator is a function of both physical and chemical kinetic properties is well established, rendering difficulties in quantitatively relating the number with fundamental homogeneous chemical kinetic measurements. $D C N$-based methods have found utility for experimentally characterizing the relative autoignition reactivity of ethanol and butanol mixtures with n-heptane [81,98] and diesel fuels [81], as well as for pure oxygenated fuel candidates and their mixtures with n-heptane and diesel fuel [76].

Others have investigated modeling of $D C N$-based multi-phase autoignition observations to adjust low temperature chemical kinetic models to improve cetane predictions [99], or as an experimental source of validation information for detailed kinetic model development relevant to low volatility diesel and gas turbine surrogate fuel mixtures, e.g. [67]. The injection-to-injection variation in experimental observations alone (up to six $D C N$ numbers) with only a single observable and the required complex multi-phase modeling interpretation make it difficult to assess the kinetic model uncertainties associated with the simulations. Schofield [100] and others [101] have recently commented that detailed chemical kinetic models themselves are essentially well considered engineering constructs, as noted in the title of the Schofield paper: Adequate as Engineering Models-No More, No Less. This is the basic reason that there are a plethora of kinetic models in the literature, all existing for the same fuel, and the stimulus for introducing concepts such as PrIMe [102]. Every model published today will continue to evolve in mechanism and thermochemical/kinetic parameters as science advances. Such models are powerful tools for discovering new science and analyzing observations of applications. However, refining mechanistic details or parameters in a detailed kinetic system, on the basis of fluidchemistry calculations compared against such applications data for a limited number of observables appears risky.

Other well developed experimental methods used for investigating the relative importance of physical and chemical fuel properties for emulating multi-phase combustion are available and already use multiple diagnostic capabilities [103]. These facilities have been utilized for refining current diesel spray models through experiments in optically accessible, constant-volume highpressure environments, with prototype and commercial injectors, non-reacting [104] or reacting [105] gas mixtures, over the ranges of gas pressures and temperatures found in engines. Additional details regarding several different facilities capable of performing such experimental studies can be found in [103]. Non-reactive data to evaluate physical/chemical properties effects are collected through high speed visual and optical diagnostic imaging as a function of fuel properties and typically include liquid and vapor penetration characterization. For combustion cases, imaging and optical diagnostics are applied to determine ignition delay, flame lift-off length, soot volume fraction, and morphology (through soot sampling) data [106, 107]. The experimental observations are valuable for characterizing integrated physical and chemical fuel effects on multi-phase combustion behaviors, including sooting.

Figure 5 displays liquid and vapor penetration length and mixture-fraction distribution for a non-reacting experiment conducted with n-dodecane as fuel, along with numerical model predictions [66]. The comparison of experiment and modeling results were part of an effort to develop a skeletal $n$-dodecane kinetic model for use in spray combustion simulations. The data displayed in Figure 5 are qualitatively similar to data obtained at other conditions and for other liquid fuels. 
Typical results on how alternative fuel properties affect liquid spray and vapor penetration are documented in the recent work of Kook and Pickett on comparison of alternative and petroleum derived diesel fuels [104]. In this work, the liquid penetration length was shown to correlate reasonably well with fuel volatility typically represented by $T_{90}$, the distillation temperature at which $90 \%$ of the liquid fuel distillation has been recovered as vapor. Additionally, the length was found to be roughly proportional to the liquid density. Other properties such as viscosity, surface tension, and heat of vaporization also affect liquid penetration length which quickly reaches a quasi-steady value after start of injection. However, the vapor penetration length normal to the liquid jet continues to grow downstream of the liquid penetration length at nearly a fixed spreading angle. For the fuels studied in [104], vapor penetration and spreading angle were found to be only weakly dependent on fuel volatility or density. The fuels of different density and volatility had different liquid penetration lengths but nearly the same vapor penetration and spreading angle. The authors concluded that all cases displayed the same total ambient gas entrainment and fuel vapor-gas mixing. Figure 6 depicts the relationship of these physical parameter indicators qualitatively with combustion observations including sooting properties.

These experiments amply demonstrate that the complexity of direct injection compression ignition applications requires compact and well-considered approximations for coupling physical and chemical property effects in modeling real fuel impacts on observations.

\subsection{Sooting and Average Molecular Weight Indicators}

Both experimental and theoretical fundamental studies of sooting behavior in flames and their relationship to specific organic structure have provided a foundation for characterizing sooting behaviors of real fuels $[108,109]$. The following discussion is motivated by the relevance of considering sooting indicators in formulating mixtures of components to emulate real fuel behavior in practical combustion applications.

Smoke point (SP) is generally used as a sooting tendency indicator for jet fuel specification, but there is no similar reference indicator specified in standards for gasoline or diesel fuels. However, $S P$ can be valuable in formulating mixtures of known species to reproduce sooting tendency, particularly for diesel fuels, and as an indicator impacting particulate formation.

Smoke points are experimentally determined by the ASTM D1322 smoke point test method [110] or a similar standardized smoke point variant [111]. Smoke point refers a wick flame height at which incipient sooting appears at the flame tip, the higher the $S P$, the lower the sooting tendency of the fuel. Minimum smoke point standards for petroleum derived, and alternative jet fuels and their blends are limited to $25 \mathrm{~mm}(18 \mathrm{~mm}$ for fuels containing less than $3 \mathrm{vol} \%$ naphthalenes). Sooting tendency of a fuel is not only important to emissions, see for example [112], but to radiative thermal loading in gas turbine combustors [113].

Historically, $S P$ measurements made in various devices and laboratories were inconsistent with one another, and Calcote and Manos [114] resolved many of the disparities by defining a Threshold Sooting Index (TSI) based upon smoke point measurement and the molecular weight $(M W)$ of the fuel. To quantitatively compare the sooting tendency of various hydrocarbons, they proposed TSI to have a reference scale from 0 to 100 defined by the TSI values for two reference species as, 


$$
T S I=a(M W / S P)+b .
$$

The constants $a$ and $b$ are apparatus-dependent and defined to result in TSI values of zero to 100 based, based upon the sooting measurements for high and low sooting tendency reference species Mensch et al. used 1-methyl naphthalene $(T S I=100)$ and methylcyclohexane $(T S I=0)$ to define $a$ and $b$ to derive a consistent set of TSI data based upon published literature data and additional experimental measurements performed using the standard smoke lamp specified in ASTM D1322 [110]. For the case of mixtures of species, the TSI approach of Gill and Olson [115] was also adopted by Mensch et al. [116], who proposed and tested a linear mixing rule of TSI component values weighted by their mole fractions, $x_{i}$ :

$$
T S I_{m i x}=\sum_{i} x_{i} T S I_{i} .
$$

The linear mixing rule was experimentally confirmed by studying mixtures of different components derived to produce the same TSI.

The sooting tendency as a function of molecular class structure generally is aromatics > cyclo-alkanes > iso-alkanes > normal alkanes. Discerning accurate smoke points for pure components having low SPs (high sooting tendency, e.g. aromatics) and high SPs (low sooting potential, e.g. paraffins) are not reliable as a result of flame height dimensional resolution at the soot breakthrough condition. To avoid these difficulties, particularly for aromatics, McEnally and Pfefferle [117, 118] proposed a similar sooting tendency scale based upon the maximum soot volume fraction, $f_{v, \max }$, measured along the centerline of a nitrogen-diluted methane diffusion flame doped with small quantities of the compound of interest. Laser induced incandescence intensities were measured at different heights in the flame and a linear expression for calculating the Yield Sooting Index (YSI) of a compound was proposed in the form,

$$
Y S I=c f_{v, \text { max }}+b
$$

where $c$ and $b$ are constants used to scale the values of $f_{v \text {,max }}$ based upon two chosen reference species. YSI is particularly valuable for defining sooting tendency of many aromatic compounds found in petroleum derived diesel fuel [119], but values for the alkane fractions found in fuels remain difficult to determine. Mensch et al. concluded in their work that when properly rescaled, a consistent set of TSI values could be assembled and that both TSI and YSI results can be used in developing a single, consistent set of sooting tendency indicators.

However, emerging alternative aviation and other fuels, particularly those with essentially no aromatic content, can have such low sooting tendencies that a smoke point measurement cannot be performed (SP > $50 \mathrm{~mm}$ ) using ASTM D1322 methods (or with the YSI approach). This fact frustrates fuel characterization of low sooting pure species, neat alternative fuels, and predicting sooting for blends of them with petroleum derived jet fuels [120,121] or for applying these techniques to compare the sooting potentials of gasolines or diesel fuels. Recently, we have demonstrated a method to determine quantitative ("virtual") SPs that exceed $50 \mathrm{~mm}$, in a manner consistent with ASTM D1322 smoke point methods and apparatus [122]. The same principles can also be applied to obtain more accurate estimation of $S P$ for highly sooting pure species and mixtures.

An important uncertainty associated with experimentally determining the TSI of a mixture of components is that of determining a mixture averaged molecular weight, $M W_{\text {ave }}$. We have 
recently developed a new methodology to experimentally determine $M W_{\text {ave }}$ of fuels with distillation ranges typical of gasoline, gas turbine, and diesel fuels that characteristically yields data with an uncertainty of less than $6 \mathrm{~g} / \mathrm{mole}$ [123]. Other work has concluded that strained extinction measurements of diffusion flames can be better understood in terms of transport, chemical kinetic, and energy potentials of fuels by considering the fuel $M W$ [124]. Moreover, the above work of Pera and Knop [92] on simulating real gasolines also used $M W_{\text {ave }}$ as one of the formulating criteria. Thus, accurate determination of real fuel $M W_{\text {ave }}$ is relevant to several fuel properties utilized in analyzing combustion.

Recently, it has been suggested that the inclusion of $M W$ in the correlation function for sooting is unnecessary and not supported by theory $[125,126]$. Despite attempts to remove the shortcomings of the TSI correlation method, Watson et al. [111] have pointed out that the normalized soot point method that was proposed as an alternative continues to suffer from large errors for fuels with low sooting potential. Thus, Watson et al. investigated a more precise method to determine the sooting point phenomena based upon fuel uptake rate measurement with threshold imaging (FURTI) to define the soot breakthrough condition. The fuel uptake rate at the point when the flame showed maximum sensitivity to mass flow rate was substituted in equation (2) for SP, vastly improving the uncertainty in determined TSI values for pure components and mixtures. The sooting tendency of paraffin components found in diesel and gasoline fuels have also been compared in similar wick flames using differential mobility spectrometry [127]. Other fundamental studies on soot volume fraction characteristics for different fuels in similar wick flames have also been reported. Finally, Barrientos et al. [128] have recently suggested a modification of the TSI relationships, an Oxygen Extended Sooting Index (OESI) to represent the influence of oxygenated fuel species on sooting tendency. Barrientos applied a functional group analysis to their data to attempt to relate oxygenated structural contributions as had been done earlier for pure hydrocarbons [129] and oxygenated hydrocarbons [130] with TSI data.

Presently, conventional smoke points measured in various apparatus configurations continue to be used as a parameter for characterizing kerosene surrogate fuels via the Threshold Sooting Index (TSI) [116, 131], as a parameter in correlating experimental pool fire mass burning rates, [132], as a submodel input for turbulent combustion simulations [133] and in formulating surrogate fuel mixtures, discussed below. Similar approaches may be useful in considering fuel property effects in gasoline and diesel fuel sooting studies and as another target for formulating mixtures of components to represent real gasolines and diesel fuels.

\subsection{Advances in Chemical Analysis Methods}

Advances in chemical analysis tools and informatics have immense potential for improving characterization of the chemical and physical properties of real liquid fuels. Many of these tools have been used in the petroleum refining field for a number of years, but are only now emerging in importance to combustion research.

Octane and cetane indicators are strong functions of the organic structural composition of a

fuel. The early work of Indritz and co-workers [134] using ${ }^{13} \mathrm{C}$ nuclear magnetic resonance (NMR) as a diagnostic clearly demonstrated that functional group additivity concepts (similar to those applied in predicting chemical thermodynamic and kinetic properties [135]) can be applied to predict the $C N$ of single species as well as mixtures. NMR characterization synergizes with advances in paraffin, iso-paraffin, olefin, naphthenes, and aromatics (PIONA) organic class structure measurements, gas chromatographic (GC) field ionization mass spectrometry (FIMS) 
and GC x GC based hydrocarbon flame ionization detection (FID) that all characterize fuel molecular properties [136]. Figure 2 is an example of GC x GC characterization of the detailed chemical composition of a real diesel fuel [137].

NMR analysis provides complementary specific structural information regarding hydrocarbon mixtures that can be related to both physical and chemical properties of the fuel. ${ }^{1} \mathrm{H}$ and ${ }^{13} \mathrm{C}$ NMR can accurately resolve specific functional carbon types, e.g., $\alpha$-methyl $\left(\mathrm{CH}_{3}\right)$, and $\beta$-, $\gamma-, \delta$-, and $\varepsilon$-methylenes $\left(\mathrm{CH}_{2}\right)$, etc. and quantify important structural groups such as aromatic, cyclo paraffinic, normal paraffinic, and branch paraffinic groups. The data can be further processed to reveal additive functional group correlations. NMR analysis thus differs from more traditional molecular analysis methods, but molecular composition can be determined through appropriate mathematical algorithms.

As early as 1990, Cookson and Smith [138] applied NMR to characterize a number of fuel properties for both diesel and jet fuels. Detailed molecular structure information derived from ${ }^{1} \mathrm{H}$ and ${ }^{13} \mathrm{C}$ NMR spectra correlated with detailed chemical species data has been utilized to determine a wide range of chemical properties [139, 140]. Since 1994, on-line process NMR applications have applied partial least-squares (PLS) regression modeling, in which entire (or partial) NMR spectral variability is regressed against chemical and physical parameter values obtained from primary ASTM test methods. Regression correlations have been made for a wide range of gasolines between ${ }^{1} \mathrm{H}$ NMR and $R O N, M O N$, distillation parameters $\left(T_{5}, T_{10}, T_{50}, T_{90}\right.$, $T_{95}$ ), benzene content, aromatic content, olefin content, oxygenate content (MTBE or ethanol), and liquid density, with sufficient accuracy to certify at a refinery gasolines entering the commercial pool. Anjular et al. [141] have applied similar correlation approaches for characterizing petroleum derived and alternative diesel fuel specification parameters, including $D C N$ and flash point. Bays and King [142] recently performed a carbon type analysis of 14 different diesel fuels to compare molecular structural differences for ultra-low sulfur, renewable, and alternative diesel fuels. This reference is particularly enlightening in terms of demonstrating the reproducibility of ASTM specification parameters and advanced analytical measurements across several laboratories.

At the same time, advances in applying quantitative structure property relationship (QSPR) and quantitative structure activity relationship (QSAR) techniques have led to improved predictions of cetane number [143-145], flashpoint [144], density and viscosity [146], melting point [147], heat of combustion [147], and laminar burning velocities of biofuels [148]. Recently, Saldana et al. [149] have suggested QSPR based methods for formulating alternative fuels for specific applications.

Finally, the analytical methodologies briefly discussed above can be applied to new fuel molecular components derived for renewable resources to yield quantitative information on the relevance of particular oxygenated organic structures to fuel physical and chemical properties affecting combustion. These same methods can also guide fuel refining processes to yield fuel chemical species compositions [68, 150-152] that optimize performance and reduce emissions.

\subsection{Multi-phase Combustion Modeling with Real Fuel Properties}

Representing the properties of real fuels in multiphase combustion environments requires a mixture of many known components and a variety of organic classes. Quantitative emulations of liquid density, viscosity, surface tension, distillation curve and organic class distribution across the distillation curve are required. Suitable chemical kinetic behaviors for each molecular class 
and their interactions must be represented in engineering design models. The most complex of approaches for direct injection engines are only recently incorporating sufficient modeling simplifications to consider distillation class distribution using large numbers of components, and grouping their kinetic behaviors by organic structural considerations.

For example, Yang et al. [153] developed a multi-component fuel evaporation model to represent the properties of a real gasoline during spray injection/atomization/evaporation. The components of the fuel were selected to include all of the classes of organic structures found in petroleum derived fuels. A surrogate mixture of the components was optimized to represent the fuel organic class and molecular weight distributions across the real fuel distillation curve, producing a library for all of the real fuel physical/chemical properties. The chemical kinetic behavior of the surrogate fuel was developed separately by assembling a model from five selected kinetic descriptions of species representing the collective kinetic interactions of each of the five organic classes.

Methods for integrating the predicted vaporization behavior with the chemical kinetic descriptions were investigated through two exemplar cases related to gasoline applications. In each, the local fuel vapor mixture composition was defined through a blending cetane number approach to formulate the fuel vapor mixture cetane number, based upon composition. The cetane number was then used to derive the local octane number by cross-correlation to investigate gasoline combustion properties. Simulations of single-droplet and spray evaporation with discrete multi-component fuel cases from normal evaporation to flash boiling were performed and compared with available experimental data, with promising results. A $G$-equation flame propagation combustion model was also compared with experimental data for flame speeds. Finally, direct injection engine simulations were compared with experimentally measured in-cylinder pressures.

More recently, Krishnasamy et al. [154] performed a similar work to investigate low temperature engine combustion behavior of three diesel fuels with cetane numbers ranging from 40 to 57. The same hybrid surrogate modeling approach as described above was used to represent each of the different fuel physical and chemical kinetic properties. A discrete multicomponent fuel model [155] and a species library (Figure 7) composed of component physical properties that span the hydrocarbon classes and boiling point range was used to represent the distillation curve and all physical properties of each fuel. A detailed description of the multi-component vaporization model and the method of estimation of distillation profiles appear in [155]. Up to two species of each class structure were used to develop the physical surrogate composition. Four other species were used to characterize the kinetics for each molecular class used in the physical property description (Figure 8).

Each of the formulated multi-phase diesel surrogate models were applied to predict conventional and low temperature combustion (LTC) characteristics for experiments conducted in a single cylinder diesel engine using an in-house code incorporating a "MultiChem" kinetic model composed of 120 species and 459 reactions. Calculations were also compared with those using a single component surrogate with the physical properties of n-tetradecane and the chemical kinetic properties of $n$-heptane. Predictions compared favorably with experiment and both modeling approaches for conventional diesel operations, but the single component model was unable to predict combustion and emissions for LTC conditions, especially for lower cetane cases, as would be expected. This work illustrates the utility of reference indicators in constructing such models and their complexity in terms of developing detailed dependencies on both fuel physical and chemical kinetic properties. 
The methodology of splitting physical and chemical property estimation methods using different representative species for each has been applied frequently but with fewer rigors than above. For example, Kerschgens et al. recently used toluene to represent the physical spray properties, and reduced kinetics of a mixtures of n-heptane, iso-octane, toluene, ethanol, dimethyl ether, phenol and ethane to represent the kinetic aspects for simulation of direct injection diesel combustion with 2-methyl tetrahydrofuran, di-n-butyl ether, and their blends as fuel [156]. The purpose of the exercise was to build a platform for rapid initial diesel simulations using new oxygenated alternative fuels. Predictions qualitatively reproduced experimental engine pressure history and emissions.

A somewhat different approach has been applied to represent physical and chemical properties of real fuels in gas turbine combustion simulations [157-159]. The multi-component properties of a Jet A-1 and two alternative jet fuels were described by continuous mass fraction distributions as a function of molar mass for each chemical class structure. Each class was modeled with three $\Gamma$-probability distribution functions. A single class component was assigned to each as the mass to be transported and to serve as the chemical kinetic modeling descriptor ( $\mathrm{n}$ decane, cyclo-pentane, benzene) and spray evaporation was formulated using continuous thermodynamics as opposed to a classical multi-component evaporation description. The approach was applied to compare n-decane and the Jet A-1 fuel sprays with data from laminar [157] and turbulent [158] flow experiments. Combustor modeling comparisons were also performed and included two additional alternative fuel formulations, one generated from coal, and another generated from natural gas [159]. Preferential vaporization effects led to different local liquid volume concentrations and vapor mass concentration fields of the reaction intermediate and product species in the combustion simulations. Differences in acetylene levels among the predictions were suggested to indicate potential differences in soot emissions. However, only small differences in the volumetric heat release envelope of the primary combustion zone were observed for the various test fuel cases.

The above examples clearly demonstrate the levels to which simplifying approximations must be made to incorporate real fuel properties into computational design tools. All use fuel $\mathrm{H} / \mathrm{C}$ ratio as a reference indicator for emulating the real fuel chemical properties with mixtures. However, there is no standard autoignition reference indicator for gas turbine applications. Recently, our jet fuel research introduced the use of $D C N$ as a "relative reactivity indicator" for gas turbine fuels [160,161], a concept now more widely accepted. For example, Kim et al. [162] recently used $D C N$ along with other property indicators to construct a single surrogate composition for replicating both chemical and physical properties of real jet fuel behavior. Surprisingly, the threshold sooting index (TSI) incorporated in their earlier work [163] was not considered. Below the consideration of reference indicators and methods on selecting components and defining mixtures of components to consider multi-phase applications is further discussed.

\section{Surrogate Mixture Concepts and Approaches for Emulating Real Fuel Combustion Behavior.}

Using mixtures of known components (surrogate mixtures) to investigate the combustion properties of a real fuel historically began as an exercise in providing specification reference indicators for real fuels in a time when little could be understood quantitatively other than through engineering empiricism. Overviews such as [164, 165] and the early efforts such as 
$[129,163,166-168]$ quickly recognized the need for larger numbers of surrogate components to replicate multi-phase applications and introduced early consideration of NMR to developing surrogate strategies to improve emulations of sooting tendency for jet fuels $[165,169]$.

Experience gained in European direct injection diesel [170] and gas turbine combustion [171] programs and a series of workshops [172] and follow-on discussions led to reviews and road maps for advancing surrogate fuel research and model construction relevant to gasoline [93], diesel [173], and jet fuel [174]. Emphasis was placed upon pre-vaporized chemical kinetic/physical property aspects, considering multiphase surrogates to be a future task. A collection (palette) of surrogate components from which to generate mixtures of components (surrogate fuel compositions) for each type of petroleum derived fuel was developed and prioritized by the state of detailed kinetic modeling knowledge for each component. Property targets to be replicated by the surrogate components and mixtures, development targets for testing and validating physical and kinetic models, and applications targets were discussed, along with methods to dimensionally reduce the model representations.

More recently, a comprehensive review of diesel surrogate research appeared in 2011 [175], and another work further emphasized the need for and complexity of representing physical properties of aviation gas turbine fuels [176]. Tools for estimating physical properties of components and mixtures were advanced substantially in sophistication [177], and the resulting criteria were applied to evaluate the "physico-chemical authenticity" of a number of previously proposed jet fuel surrogates $[178,179]$. Impressive progress has been made on detailed chemical kinetics related to the original fuel palettes [93], [173], [174] and in developing model reduction methods e.g. see [63, 180]. Efforts have improved kinetic descriptions of n-alkanes [181] and weakly branched alkanes [182] over a wide range of carbon numbers [183], with further work on n-and iso-cetane [27, 184], cyclo-alkanes [185] and decalin [186]. Higher molecular weight alkyl aromatics [187], including those found in diesel fuels [188, 189] are continuing to be addressed. Tools to create kinetic models more rapidly by using reaction class construction methods, for example, [181-183], or by computational mechanism generation [63, 180, 190, 191], have become more widely applied. Tools to assemble multi-species fuel models, along with multiple approaches to numerically reduce constructs have also become available through several commercial enterprises.

\section{Some Comments on Selecting Surrogate Components and Testing Mixture Behaviors}

Here remarks, are limited to brief commentary on the state of the field from a personal perspective gained from involvement in surrogate fuel work beginning prior to 2007 [192] and driven by an even longer term fascination with engineering applications [193]. A first pragmatic observation is that combustion-related behavioral aspects of a real fuel and another fuel are best quantitatively compared to each other by actual experiments involving each over a wide range of venues, from fundamental to applied scale.

However, a potential alternative (certainly a powerful supplement) to experimental testing and complex model comparisons is emerging, as demonstrated in a recent work on developing diesel surrogates [77]. The hypothesis of the approach is that if all of the engineering parameters used to characterize a real fuel are known, along with detailed knowledge of its chemical structural composition, then a surrogate mixture developed to share the same collective characteristics will have identical combustion behaviors. There is justifiable optimism that 
replicating the chemical structural characteristics represented by the collection of species found in any fuel can be the most appropriate quantitative target for a surrogate mixture [194]. If a surrogate mixture composition shares the same functional group distributions over the distillation curve as the real fuel, then all of the fuel combustion property-related behaviors will be closely shared in any combustion configuration.

In Mueller et al. [77], quantitative ${ }^{1} \mathrm{H}$ and ${ }^{13} \mathrm{C}$ NMR spectral integrals and elemental analyses of the target fuel were used to define eleven carbon types (among the ninety-nine carbon elemental groups) in the real fuel based upon a hypothesis that the chosen groups should allow the sooting and other characteristics over the range of diesel fuel properties to be represented. Through optimizing differences in fuel properties of the real fuel and surrogate composition, an eight-component surrogate was determined from a larger library of choices that included representation of each hydrocarbon class: (3) normal alkanes, (1) iso-alkane, (1) cyclo alkane, (1) cyclo-naphtho aromatic, and (2) alkyl aromatics. Only the cycloalkane had an alkyl side chain longer than $\mathrm{CH}_{3}$. It was demonstrated that the reference indicators for diesel fuels and physical/chemical properties of a real fuel could be recovered to reasonable accuracies by mixtures with as few as eight surrogate components.

The level of characterization of fuels and surrogate model development through this fundamental formulation approach is receptive to including modified or new reference indicators and additional classes or functional groups to represent oxygenated alternative fuels, and the approach yields a surrogate that should be physico-chemically authentic [178, 179]. Several important matters are left unresolved. For example, it is unclear whether analyses at the carbon bonding level or at a functional group level may be more advantageous, or whether further reductions in the numbers and classes of surrogate components might be possible. Finally, using separate component mixtures for physical and chemical kinetic properties similar to those employed by [154] might also permit simplifications in the needed kinetic models.

It is interesting to note that the formulated surrogate did not replicate the molecular class composition of the subject real fuel. The investigation on jet fuels noted above [192] offers some further insights on this result. Dryer and co-workers developed an a priori methodology to formulate surrogate mixtures for vapor phase combustion, requiring only limited knowledge of the molecular class composition of the specific real fuel. A real jet fuel is composed of generic chemical class structures that through their reactions collectively contribute producing a much smaller pool of distinct chemical functionalities (Figure 9). These distinct chemical functionalities define the "active radical pool" through their further reaction, which in turn is responsible for abstracting hydrogen from the original fuel components. If there is little interaction amongst the large radicals produced in the abstraction process, then the major organic classes found in jet fuels primarily produce three distinct chemical functionalities: n-alkyls, isoalkenyls (generic isomerized alkene sources) and benzyl-type functionalities. Initially, Dryer et al. assumed cycloalkanes did not represent additional distinct functionalities beyond those already available from the reactions of normal-alkanes and iso-alkanes in the presence of significant aromaticity. Further reactions of the distinct functionalities to form fragments of $\mathrm{C}_{4}$ and smaller, eventually regenerates the radical pool leading to the hydrogen abstraction reactions that along with thermal decomposition consume the original fuel components. In principle, if a fuel generates the same distribution of distinct chemical functionalities, the actual molecular class fractions of the fuel do not necessarily need to be reproduced in order to share the same global combustion properties. Each molecular structure of the original fuel composition may contribute to the pool of several distinct functionalities. And, in fact the complex compositional 
structure of a real fuel suggests that its reactions produce an interacting radical pool of many specific fuel structures, evolving over the reaction history, a situation very different than the evolution of a radical pool specific to the pyrolysis/oxidation of a single species.

This conceptual theory was applied early-on to select a set of reference indicators - DCN,

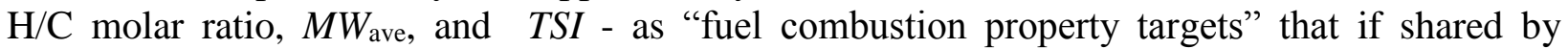
another fuel, would result in similar fully prevaporized global combustion behaviors. A minimal set of surrogate components were selected based upon their ability to contribute to the three distinct functionalities mentioned above. A $1^{\text {st }}$ generation surrogate composition (n-dodecane, iso-octane, and toluene) was defined that could emulate the $\mathrm{H} / \mathrm{C}$ ratio and $D C N$, but not both the $T S I$ and $M W_{\text {ave }}$ of the specific reference real fuel simultaneously, with the intention that there were developed models for its components to offer an analysis of the results. A $2^{\text {nd }}$ second generation composition ( $\mathrm{n}$-dodecane, iso-octane, 1,3,5, trimethyl benzene, and n-propyl benzene) was found to replicate all four property target combinations. The formulation methodology was tested experimentally in a wide range of venues and experimental conditions to compare real fuel and formulated surrogate mixture global combustion, with the expectation that additional property targets might emerge. The method was proofed using a Jet A fuel sample (POSF 4658) and a synthetic paraffinic kerosene (POSF $4773 \mathrm{~S}-8$ ) as fuel targets [120, 161]. A wider range of JP-8 fuels and fully hydrogenated, synthetic fuels from natural gas, coal, and bio oils and alcohols has since been similarly studied [120, 121, 161, 195]. Higher molecular weight nalkanes and iso-alkanes have been added to the $2^{\text {nd }}$ generation surrogate component pallet [195, 196], and the surrogate concept has also been shown to apply to producing mixtures of multispecies hydrocarbon fluids, including other fuels, to emulate the global combustion properties of a target jet fuel $[131,197]$.

On the basis that the surrogate fuel closely replicated the combustion behavior of the real Jet A fuel (even at the detailed intermediate species level [120]), a simple functional group additivity analysis was applied to the $1^{\text {st }}$ generation and several different $2^{\text {nd }}$ generation surrogate compositions that all closely shared the same property targets. The findings are enlightening. Discounting the small amounts of carbon present as $\mathrm{CH}$ and quaternary carbon, it was found that all of the mixtures represented nearly identical molar distributions of $\mathrm{CH}_{2}$, (methylene) $\mathrm{CH}_{3}$, (methyl) and $\mathrm{C}_{6} \mathrm{H}_{5} \mathrm{CH}_{2}$ (benzyl) functional groups [121]. The collection of the combustion property targets apparently serves as descriptors for a quantitative chemical structure-chemical property relationship (QSPR), supporting that surrogate compositions can be simpler than those suggested by replicating each molecular class found in a real fuel at a higher level than considering individual chemical bonding.

Normal- and iso-alkanes typically dominate the class composition of all-fit-for-purpose, petroleum derived fuels, and the peak active radical pool produced in the oxidation of each class present is ordered as n-alkanes $>$ iso-alkanes $>$ cycloalkanes $>$ aromatics [94]. Methyl and methylene groups are the primary constituents of the alkanes, with the number of consecutive methylene groups defining the chain length of n-alkyl radicals. The propensity of an n-alkyl radical to undergo the lowest activation energy alkyl peroxy radical isomerization requires at least three successive $\mathrm{CH}_{2}$ groups in the molecular structure. As the carbon number of an $\mathrm{n}$ alkane radicals increases, the probabilities for oxygen addition to form hydroperoxides and ketohydroperoxides yielding degenerate branching also increases. Thus one might expect a diminishing constraint on low temperature activity with increasing alkyl carbon chain length.

Figure 10 compares VPFR reactivity data for a series of $n$-alkane fuels from $n$-heptane to n-hexadecane, all at the same carbon loading and at an equivalence ratio of one [198-200]. 
There is a significant increase in low temperature and negative temperature coefficient reactivity as carbon chain length increases from n-heptane to n-decane, with smaller increases occurs with increasing carbon number from n-dodecane to n-cetane, as evidenced in the oxygen, carbon monoxide, water, and formaldehyde reactivity profiles. Cetane number differences are strongly correlated with increasing carbon chain length from ten to twenty [201]. Finally, the beginning and end of $L T H R$ and the beginning of ITHR (coinciding with the hot ignition transition) are clearly delineated by the formaldehyde reactivity profiles (Figure 10d). As noted earlier, the second formaldehyde profile defining the end of ITHR and beginning of HTHR is related to the collective failure of the hydrocarbon fragments to inhibit oxidation of carbon monoxide through competition for $\mathrm{OH}[94,193,202]$.

The ratio of methyl to methylene groups is also indicative of the degree of branching present in an iso-alkane. The site(s) where branching occurs affects the structure of the resulting alkyl radicals, the distribution and structure of alkenyl fragments formed [193], and hence the small species kinetics that regenerates the radicals consumed through fuel destruction. The extent of methylation in the fuel structure (extent of isomerization) reduces the radical regeneration per radical consumed in comparison to n-alkanes and hence the overall radical pool diminishes by iso-alkane addition to a reacting mixture of n-alkanes. This result is in evidence in the PRF mixture reactivity profiles shown in Figure 4.

It is equally important to recognize that the ignition delay time for fundamental oxidation experiments of pure components and their mixtures, characterized by heat release, $\mathrm{OH}$ radical growth, or maximum $\mathrm{CO}+\mathrm{CO}_{2}$ emission again denotes the characteristic time at which rapid oxidation of the remaining $\mathrm{CO}$ occurs. Figures 11, 12 compare predicted fuel consumption and $\mathrm{C}_{2}-\mathrm{C}_{4}$ olefin profiles for the isochoric, adiabatic oxidation of hydrogen, methane, n-heptane, ncetane, and iso-cetane as a function of time normalized by their respective ignition delay times. The predictions are compared for three different initial reaction temperatures and two different pressures. In Figure 11, hydrogen and methane cases are unique in that little fuel is consumed prior to the occurrence of the predicted ignition, primarily due to slow initiation reactions. The fuel disappearance of each of the other fuels changes with pressure and temperature, molecular chain length, and isomeric structure. The nature of these effects produces significant differences in $\mathrm{C}_{2}-\mathrm{C}_{4}$ olefinic species distributions over the ignition delay period (Figure 12). Though not shown, the composition of the $\mathrm{C}_{2}-\mathrm{C}_{4}$ olefin fraction profiles also vary with fuel and conditions.

Low and intermediate temperature as well as high temperature kinetic behavior of alkane mixtures are also significantly affected by the addition of benzyl type functionalities, primarily because of the unique stability of the radical site located at the alpha position to an aromatic ring, which is characteristically reliant on bimolecular reaction for consumption. The reactivity characteristics of n-propyl benzene, 1,2,4-trimethyl benzene, and 1,3,5-trimethyl benzene are compared in Figure 13a. It is noted that the presence of a longer alkyl side chain in n-propyl benzene leads to the lowest hot ignition transition temperature. None of these aromatics display significant low temperature oxidative activity. Though the individual oxidative behaviors of each alkyl aromatic are different, the addition of each to n-decane results in the same inhibition of low temperature reactivity and hot ignition properties for the binary mixtures (Figure 13b, c). This is to be expected as they each represent the same chemically distinct functionality discussed earlier.

At higher temperatures, the decomposition and oxidation rates of the benzyl species formed are considerably slower than those for alkyl and iso-alkyl species, leading to delayed oxidation of their carbon content in comparison to the alkane. These interactions have significant effects on 
the chemical composition of alkenyl species and heat evolution with extent of destruction of the original fuel species over the ignition delay period. It should be noted that multi-phase atomization, vaporization, and fuel vapor-air mixing will yield a complex temperature and mixture history that may also affect $\mathrm{C}_{2}-\mathrm{C}_{4}$ olefin distribution and time history.

Producing mixtures of components to replicate the properties of a single molecular species is also instructive in terms of distinct functionality characteristics, selecting surrogate components, and component classes. For example, the presence of longer normal alkyl side chains on benzyl functionalities are of special interest to diesel fuel characterization. Normaldecyl benzene was suggested as a surrogate component for diesel applications [173] and it is difficult to generate fundamental experimental data for such heavy hydrocarbons. The molecular weight of such hydrocarbons presents significant experimental difficulties in producing gas phase kinetic reference data. Recently Darcy et al. [188] investigated approximating the behavior of this species with mixtures of n-propyl or n-butyl benzene with n-heptane. While the $\mathrm{H} / \mathrm{C}$ ratios of the mixtures were matched to those of $\mathrm{n}$-decyl benzene, no kinetic data on the target fuel was available to compare with that for the two mixtures suggested as surrogates.

However, the chosen surrogate compositions do not appear to simulate the kinetic behaviors of n-decyl benzene well. This can be concluded by comparing the DCN and TSI reference indicator property targets for the surrogate mixtures with ones estimated for n-decyl benzene. The cetane number of n-decyl benzene must lie between those for n-octyl benzene $(\sim 50)$ and $n-$ dodecyl-benzene $(\sim 68)$, in the range of $\sim 58$ [134, 201]. This value is much higher than the cetane numbers estimated from data in the literature and linear volumetric mixing rules for the surrogates of n-propyl benzene/n-heptane ( 32.4) and n-butyl benzene/n-heptane ( 28.5) recommended by Darcy et al. The disparity results from the fact that the fractional contributions of the adjacent $\mathrm{CH}_{2}$ groups present in the surrogate component mixture do not provide the same probability that the n-decyl side chain offers for hydroperoxides and ketohydroperoxide formation. Essentially the distinct functionalities present in $\mathrm{n}$-decyl benzene are not provided by a mixture of these alkyl aromatics and n-heptane that matches the $\mathrm{H} / \mathrm{C}$ ratio. A mixture of a much higher carbon number n-alkane with an aromatic is required, e.g., a toluene and nhexadecane mixture yields nearly the same $\mathrm{H} / \mathrm{C}$ and $D C N$ as n-decyl benzene.

In a similar exercise, reproducing the combustion property targets of 2-methyl heptane $(2 \mathrm{mH})$ using mixtures of $\mathrm{n}$-decane and iso-octane has been [121]. The resulting reactivities of the surrogate composition and $2 \mathrm{mH}$ sharing the same $\mathrm{H} / \mathrm{C}$ and $D C N$ were shown to be identical. Though kinetic studies for weakly branched alkanes are significant for furthering detailed chemical kinetic understanding, it appears that it is unnecessary to include this molecular class in surrogate mixtures, since it produces the same distinct functionalities as mixtures of more heavily branched isomers with normal alkanes. Moreover, in real fuel compositions, there will likely be many such isomeric and carbon chain length permutations.

Finally, in reconsidering the significance of cyclo-alkanes as surrogate components, we recently added methyl cyclohexane $(\mathrm{MCH})$ to mixtures of n-decane, iso-octane, and toluene in a manner to reproduce the same combustion property targets as that of a $1^{\text {st }}$ generation surrogate composition [161] used to emulate Jet A POSF 4658 [203]. It was found experimentally that the reformulated surrogate was composed of nearly the same fractions of n-decane and toluene, with essentially an adjustment in only iso-octane fraction to include MCH. In VPFR experiments, the two surrogate compositions replicated the target fuel and each other at low temperature and high temperature global reactivities. During hot ignition transition conditions (ITHR), however, the decomposition of radicals formed through $\mathrm{MCH}$ resulted in an accelerated reaction rate. In a 
separate paper [204], similar behaviors were noted in VPFR reactivity experiments comparing surrogate component mixtures of hydrocarbon fluids with and without cycloalkane contents with the same real jet fuel. Depending on the global combustion parameters of a real fuel that are of interest, it may be that cycloalkane and iso-alkane classes are essentially interchangeable in formulating surrogate mixtures, especially when aromatic fractions are also present.

In summary, it is apparent that the assumption that all classes of organic structure found in real fuel must be available in a surrogate component palette may be overly restrictive in terms of surrogate formulations. The numbers of surrogate components needed to emulate real fuel kinetic related combustion properties may be fewer than the classes found in the fuel. Clearly, the intermediates produced in the reactions of some species are significantly different from others, and satisfactory surrogate approximations will be dependent on the details to which one wishes to reproduce real fuel combustion behavior. Of course, at some level of detail, all surrogate mixtures will fail to replicate the details of real fuel combustion characteristics. However, it can certainly be inferred by the observations presented here that chemical reactions occurring between large molecular weight radical species and fuel components or large molecular weight intermediates are of limited importance in formulating surrogates (and models) for real fuels.

Much still needs to be explored in creating a flexible and appropriate procedure for selecting the most appropriate surrogate component pallet and mixture procedures to minimize the number of components needed for replicating chemical kinetic behavior of a real fuel, while also accommodating inclusion of alternative fuel species, including various oxygenated structures. The disparity in terms of numbers of surrogate components needed to replicate distillation curve properties in comparison to the likelihood of much smaller numbers to represent kinetic behavior favors approaches separating the two needs as demonstrated in the works of Reitz and coworkers. Creating compact models for kinetics such as those produced by Reitz and co-workers $[154,205,206]$ or demonstrated in the recent work of Ranzi and co-workers [207-210] appear to be needed for introducing more detailed chemical kinetic behaviors into combustion design applications. The "physico-chemical authentic" [178, 179] approach of representing both physical and chemical properties with the same surrogate components, e.g. [162], appears more cumbersome, and less flexible in terms of considering mixtures of alternative and petroleum fuels, and more computationally intensive.

\section{Conclusions}

The world's appetite for transportation fuels derived from petroleum and other fossil resources is immense, will grow, will be unsustainable at some point, and will become infeasible in the very long term. There is no doubt that internal combustion engines running on liquid fuels in large measure derived from petroleum will remain the dominant prime power sources for road and air transportation for decades, probably for much of this century. Alternatives to petroleum derived fuels must emerge with comparatively much lower net carbon cycle emissions. The successful growth and establishment of a sustainable, profitable alternative fuels industry depends upon integrating alternative products into evolving petroleum derived gasoline, diesel, and jet fuel, with as much compatibility as possible, inclusive of fuel distribution and storage.

In the face of new engine technologies and emerging fuels not derived from petroleum, we need to understand how best to integrate the new fuel components into the changes that will occur in the market dominated by petroleum products. An important issue to improving fuel efficiency and reducing emissions through new engine design and fuels is to advance the state of 
near-term capabilities of computational design tools to encompass real fuel properties. Fuels must evolve to facilitate advanced diesel/spark ignition as well as emerging RCCI technologies while still supplying fuels to the legacy vehicle population. Advanced surrogate fuel concepts and modeling capabilities are essential to this exercise, given the limitations and costs of empirical engineering design and the practical needs for fuel standardization.

The principal thrust of this paper has been on only one of the sub-modeling areas, formulating methodologies of and constraints for representing the kinetic and physical properties of real fuels on vapor phase and multi-phase combustion system performance and emissions. It is very important for us to assist this area on a short time scale as we consider the fact that combustion is moving toward engine designs that emphasize more strongly controlling the real time history of combustion through chemistry so as to increase combustion efficiency and reduce emissions.

Finally, it is important to determine what accuracy in models is needed for reproducing the chemical kinetic and physical property effects of fuels on combustion performance and emissions. As early as my first involvement in this field at a workshop in 1978 [193], the recorded discourse includes an inquiry of the engine designers as to what accuracy of kinetic models would satisfy their needs. There was no firm answer available. I have similarly inquired many times and, even today, there appears to be no firm opinion.

\section{Acknowledgements}

I am very grateful to the Combustion Institute for inviting this contribution. It is impossible to comprehensively recognize the many associations and discussions that have shaped my interests in combustion, combustion chemistry, and fuel research, thus influencing this discourse. Certainly, early discussions with and mentoring by Prof. Irvin Glassman instilled my long term desire to focus my fundamental research on near-term application needs. A long term association with Dr. Charles Westbrook (dating to the late 70's when we first began numerical modeling collaborations) has continually stimulated my interests in and opinions concerning combustion chemistry. I have also benefitted greatly from opportunities to learn from and collaborate with fellow faculty at Princeton (Profs. Irvin Glassman, Martin Summerfield, William Sirignano, Frediano Bracco, Forman Williams, Ed Law, and Yiguang Ju), professional staff, and technical staff. Most important has been the intellectual stimulation derived from working with my students.

Recent work on representing real fuel combustion properties was principally sponsored by the Air Force Office of Scientific Research (Dr. Julian Tishkoff, technical monitor) and the Air Force Research laboratory, Dayton Ohio (through support from Barry Kiel and Tim Edwards). I wish to also acknowledge support from the U.S. Department of Energy, the Office of Naval Research, NASA, Ethyl Corporation, Mobil Research Corporation, General Motors Research, Honda Research, and Siemens Energy that provided the earlier foundation for this recent work.

Finally, I extend my thanks to Dr. Marcos Chaos, Dr. Stephen Dooley, Prof. Tanvir Farouk, Dr. Sang Hee Won, Mr. Francis Haas, and Mr. Jeffery Santner, who all contributed directly to the preparation of this manuscript, and to Profs. Eliseo Ranzi and Rolf Reitz for sharing their recent papers and materials prior to publication.

Preparation of this paper was supported by discretionary resources available to the author through Princeton University. 


\section{References}

[1] I. Glassman, Proc. Combust. Inst., 28 (2000) 1-10.

[2] J.B. Heywood, Prog. Energy Combust. Sci., 7 (1981) 155-184.

[3] Transitions to Alternative Vehicles and Fuels The National Academies Press, 2013. ISBN 978-0-309-

26852-3. http://www.nap.edu/catalog.php?record_id=18264

[4] C.E. Ridley, C.M. Clark, S.D. LeDuc, B.G. Bierwagen, B.B. Lin, A. Mehl, D.A. Tobias, Environ. Sci. Technol., 46 (2012) 1309-1315.

[5] International Energy Outlook 2013, U.S. Energy Information Administration, U.S. Department of Energy, Washington DC 20585, DOE/EIA-0484(2013) July.

[6] Annual Energy Outlook 2013 with Projections to 2040, U.S. Energy Information Administration, U.S. Department of Energy, Washington DC 20585, DOE/EIA-0383 (2013) July 2013, 2013.

[7] G.R. Timilsina, Phil. Trans. R. Soc., A 372, 20120323 (2014).

[8] G. Brownbridge, P. Azadi, A. Smallbone, A. Bhave, B. Taylor, M. Kraft, Bioresour. Technol., 151 (2014) 166-173.

[9] L. Maugeri, Geopolitics of Energy Project, Belfer Center for Science and International Affairs, John F. Kennedy School of Government, Harvard University, 79 JFK Street Cambridge MA. Discussion Paper \#2012-10, (2012).

[10] L. Maugeri, Geopolitics of Energy Project, Belfer Center for Science and International Affairs, Harvard Kennedy School, 79 JFK Street, Cambridge, MA. Discussion Paper \#2013-05, (2013).

[11] D. Freedman, Phil.Trans. R. Soc. A 372: 20120326, (2014).

[12] BP Energy Outlook 2035, bp.com/energyoutlook, (2014).

[13] G. Liu, E.D. Larson, R.H. Williams, T.G. Kreutz, X. Guo, Energy Fuels, 25 (2010) 415-437.

[14] S.M. Sarathy, P. Oßwald, N. Hansen, K. Kohse-Hoinghaus, Prog. Energy Combust. Sci., 44 (2014) 40102.

[15] M.S. Graboski, R.L. McCormick, Prog. Energy Combust. Sci., 24 (1998) 125-164.

[16] C.K. Westbrook, Annu. Rev. Phys. Chem., 64 (2013) 201-219.

[17] T.G. Smagala, E. Christensen, K.M. Christison, R.E. Mohler, E. Gjersing, R.L. McCormick, Energy Fuels, 27 (2012) 237-246.

[18] A. Salvo, F.M. Geiger, Nat. Geosci., 7 (2014) 450-458.

[19] M. Mascal, S. Dutta, I. Gandarias, Angew. Chem. Int. Ed. Engl., 53 (2014) 1854-1857.

[20] G.R. Wilson, T. Edwards, E. Corporan, R.L. Freerks, Energy Fuels, 27 (2013) 962-966.

[21] P. Lobo, D.E. Hagen, P.D. Whitefield, Environ. Sci. Technol., 45 (2011) 10744-10749.

[22] A.J. Beyersdorf, M.T. Timko, L.D. Ziemba, D. Bulzan, E. Corporan, S.C. Herndon, R. Howard, R. Miake-Lye, K.L. Thornhill, E. Winstead, C. Wey, Z. Yu, B.E. Anderson, Atmos. Chem. Phys., 14 (2014) 11-23.

[23] E. Corporan, T. Edwards, L. Shafer, M.J. DeWitt, C. Klingshirn, S. Zabarnick, Z. West, R. Striebich, J.

Graham, J. Klein, Energy Fuels, 25 (2011) 955-966.

[24] L. Rye, S. Blakey, C.W. Wilson, Energy Environ. Sci., 3 (2010) 17-27.

[25] G. Knothe, Prog. Energy Combust. Sci., 36 (2010) 364-373.

[26] D.J. Luning Prak, J.S. Cowart, L.J. Hamilton, D.T. Hoang, E.K. Brown, P.C. Trulove, Energy Fuels, 27 (2013) 954-961 .

[27] J. Cowart, M. Raynes, L. Hamilton, D. Luning Prak, M. Mehl, W. Pitz, J. Energy Res. Technol., 136 (2014) 032202-032202.

[28] P.Y. Hsieh, J.A. Widegren, T.J. Fortin, T.J. Bruno, Energy Fuels, 28 (2014) 3192-3205.

[29] L.S. Tran, B. Sirjean, P.-A. Glaude, R. Fournet, F. Battin-Leclerc, Energy, 43 (2012) 4-18.

[30] X. Lü, Y. Hou, L. Zu, Z. Huang, Fuel, 85 (2006) 2622-2631.

[31] Y. Yang, J. Dec, N. Dronniou, B. Simmons, SAE Int. J. Fuels Lubr., 3 (2010) 725-741.

[32] L.R. Cancino, M. Fikri, A.A.M. Oliveira, C. Schulz, Fuel, 90 (2011) 1238-1244.

[33] C. Arcoumanis, C. Bae, R. Crookes, E. Kinoshita, Fuel, 87 (2008) 1014-1030.

[34] L. Cai, A. Sudholt, D.J. Lee, F.N. Egolfopoulos, H. Pitsch, C.K. Westbrook, S.M. Sarathy, Combust. Flame, 161 (2014) 798-809.

[35] L. Xiaolu, C. Hongyan, Z. Zhiyong, H. Zhen, Energ. Convers. Manage., 47 (2006) 1438-1448.

[36] P. Hellier, N. Ladommatos, R. Allan, J. Rogerson, Energy Fuels, 27 (2013) 5222-5245.

[37] E. Christensen, A. Williams, S. Paul, S. Burton, R.L. McCormick, Energy Fuels, 25 (2011) 5422-5428. 
[38] L. Coniglio, H. Bennadji, P.A. Glaude, O. Herbinet, F. Billaud, Prog. Energy Combust. Sci., 39 (2013) 340-382.

[39] Y. Yang, J. Dec, SAE Int. J. Fuels Lubr., 6 (2013) 713-728.

[40] R. Daniel, H. Xu, C. Wang, D. Richardson, S. Shuai, Appl. Energy, 98 (2012) 59-68.

[41] J. Phuong, S. Kim, R. Thomas, L. Zhang, Environ. Mol. Mutagen., 53 (2012) 478-487.

[42] C. Wang, H. Xu, R. Daniel, A. Ghafourian, J.M. Herreros, S. Shuai, X. Ma, Fuel, 103 (2013) 200-211.

[43] Q. Zhang, G. Chen, Z. Zheng, H. Liu, J. Xu, M. Yao, Fuel, 103 (2013) 730-735.

[44] A.C. Davis, S.M. Sarathy, J. Phys. Chem. A, 117 (2013) 7670-7685.

[45] C. Togbe, L.S. Tran, D. Liu, D. Felsmann, P. Osswald, P.A. Glaude, B. Sirjean, R. Fournet, F. BattinLeclerc, K. Kohse-Hoinghaus, Combust. Flame, 161 (2014) 780-797.

[46] L.S. Tran, C. Togbe, D. Liu, D. Felsmann, P. Osswald, P.A. Glaude, R. Fournet, B. Sirjean, F. BattinLeclerc, K. Kohse-Hoinghaus, Combust. Flame, 161 (2014) 766-779.

[47] F. Contino, F. Foucher, C. Mounaïm-Rousselle, H. Jeanmart, Energy Fuels, 25 (2011) 998-1003.

[48] F. Contino, F. Foucher, C. Mounaïm-Rousselle, H. Jeanmart, Energy Fuels, 25 (2011) 1497-1503.

[49] N. Zhou, H. Wu, C. Lee, Q. Wang, M. Ming, P. Wang, SAE Technical Paper 2014-01-1257, 2014. doi:10.4271/2014-01-1257.

[50] H. Wu, M. Huo, N. Zhou, K. Nithyanandan, C. Lee, C. Zhang, J. Lin, SAE Technical Paper 2014-011452, 2014. doi:10.4271/2014-01-1452.

[51] E. Christensen, J. Yanowitz, M. Ratcliff, R.L. McCormick, Energy Fuels, 25 (2011) 4723-4733.

[52] G. Anitescu, T.J. Bruno, Energy Fuels, 26 (2011) 324-348.

[53] J.C. Calvert, The Mechanisms of Atmospheric Oxidation of the Oxygenates, Oxford University Press New York 2011.

[54] H. Olcay, A.V. Subrahmanyam, R. Xing, J. Lajoie, J.A. Dumesic, G.W. Huber, Energy Environ. Sci., 6 (2013) 205-216.

[55] G.T. Kalghatgi, L. Hildingsson, A.J. Harrison, B. Johansson, Int. J. Engine Res., 12 (2011) 452-465.

[56] G.T. Kalghatgi, Int. J. Engine Res., 15 (2014) 383-398.

[57] R.D. Reitz, Combust. Flame, 160 (2013) 1-8.

[58] R.D. Reitz, D. Ganesh, Prog. Energy Combust. Sci., In Press, doi:10.1016/j.pecs.2014.05.003 (2014).

[59] R.L. Speth, E.W. Chow, R. Malina, S.R.H. Barrett, J.B. Heywood, W.H. Green, Environ. Sci. Technol., 48 (2014) 6561-6568.

[60] G.T. Kalghatgi, Proc. Combust. Inst., 35 In Press (2014).

[61] R.N. Dahms, J.C. Oefelein, Phys. Fluids, 25 (2013) 092103

[62] R.N. Dahms, J. Manin, L.M. Pickett, J.C. Oefelein, Proc. Combust. Inst., 34 (2013) 1667-1675.

[63] J.M.S. F. Battin-Leclerc, E. Blurock, eds., Cleaner Combustion: Developing Detailed Chemical Kinetic Models (eds. F. Battin-Leclerc, J.M. Simmie, E. Blurock), Springer 2013.

[64] W.K. Metcalfe, S.M. Burke, S.S. Ahmed, H.J. Curran, Int. J. Chem. Kinet., 45 (2013) 638-675.

[65] C.K. Westbrook, Y. Mizobuchi, T.J. Poinsot, P.J. Smith, J. Warnatz, Proc. Combust. Inst., 30 (2005) 125157.

[66] Z. Luo, S. Som, S.M. Sarathy, M. Plomer, W.J. Pitz, D.E. Longman, T. Lu, Combust. Theor. Model, 18 (2014) 187-203.

[67] G.E. Bogin, E. Osecky, J.Y. Chen, M.A. Ratcliff, J. Luecke, B.T. Zigler, A.M. Dean, Energy Fuels, 28 (2014) 4781-4794.

[68] G.S. Cholakov, J. University of Chemical Technology and Metallurgy, 46 (2011) 217-236. (2014).

[69] Annual book of ASTM Standards Vol. 5.01-5.05, ASTM International, West Conshohocken PA., 2014,

[70] The European Committe for Standardization (CEN), https://www.cen.eu/Pages/default.aspx, (2014).

[71] ASTM D4737 - 10, ASTM International, 100 Barr Harbor Drive, PO Box C700, West Conshohocken, PA 19428-2959, United States, (2010).

[72] C.T. O'Connor, R.D. Forrester, M.S. Scurrell, Fuel, 71 (1992) 1323-1327.

[73] X. Hui, K. Kumar, C.-J. Sung, T. Edwards, D. Gardner, Fuel, 98 (2012) 176-182.

[74] P. Ghosh, K.J. Hickey, S.B. Jaffe, Ind. Eng. Chem. Res., 45 (2005) 337-345.

[75] P. Ghosh, S.B. Jaffe, Ind. Eng. Chem. Res., 45 (2005) 346-351.

[76] A. Sudholt, C. Liming, J. Heyne, F.M. Haas, H. Pitsch, F.L. Dryer, Proc. Combust. Inst., 35, In Press, doi:10.1016/j.proci.2014.06.147 (2014). 
[77] C.J. Mueller, W.J. Cannella, T.J. Bruno, B. Bunting, H.D. Dettman, J.A. Franz, M.L. Huber, M. Natarajan, W.J. Pitz, M.A. Ratcliff, K. Wright, Energy Fuels, 26 (2012) 3284-3303.

[78] V. Knop, M. Loos, C. Pera, N. Jeuland, Fuel, 115 (2014) 666-673.

[79] F.M. Haas, F.L. Dryer, Fuel, 120 (2014) 240-242.

[80] F.M. Haas, J.Y. Shim, A.M. Ramcharan, F.L. Dryer, Ignition Quality Evaluation of Valerate Alkyl Esters, Work in Progress Poster, 34th International Symposium on Combustion, Warsaw University of Technology, Warsaw, Poland Jul 29-Aug 3. Poster 5P131, (2012).

[81] F.M. Haas, A. Ramcharan, F.L. Dryer, Energy Fuels, 25 (2011) 3909-3916.

[82] X. Lu, D. Han, Z. Huang, Prog. Energy Combust. Sci., 37 (2011) 741-783.

[83] D. Vuilleumier, H. Selim, R. Dibble, M. Sarathy, SAE Technical Paper 2013-01-2622, 2013. doi:10.4271/2013-01-2622.

[84] C.V. Callahan, M.S.E. Thesis, Department of Mechanical and Aerospace Engineering, Princeton University, Princeton, NJ, November, 1995. MAE 2014-T.

[85] M. Chaos, Z. Zhao, Kazakov. A., P. Gokulakrishnan, M. Angioletti, F.L. Dryer, PRF+toluene Surrogate Fuel Model for Simulating Gasoline Kinetics, 5th US Combustion Meeting, Western States Section of the Combustion Institute and Hosted by the University of California at San Diego, La Jolla, CA. March 25-28. Paper \# E-26 (2007).

[86] S.W. Benson, Prog. Energy Combust. Sci., 7 (1981) 125-134.

[87] A. Kazakov, M. Chaos, Z. Zhao, F.L. Dryer, J. Phys. Chem. A, 110 (2006) 7003-7009.

[88] V.H. Rapp, W.J. Cannella, J.Y. Chen, R.W. Dibble, Combust. Sci. Technol., 185 (2012) 735-748.

[89] G. Shibata, T. Urushihara, SAE Technical Paper 2007-01-0220, 2007. doi:10.4271/2007-01-0220

[90] D. Vuilleumier, D. Kozarac, M. Mehl, S. Saxena, W.J. Pitz, R.W. Dibble, J.-Y. Chen, S. Mani Sarathy, Combust. Flame, 161 (2014) 680-695.

[91] P. Saisirirat, F. Foucher, S. Chanchaona, C. Mounaïm-Rousselle, Energy Fuels, 24 (2010) 5404-5409.

[92] C. Pera, V. Knop, Fuel, 96 (2012) 59-69.

[93] W.J. Pitz, N.P. Cernansky, F.L. Dryer, F. Egolfopoulos, J.T. Farrell, D.G. Friend, H. Pitsch, SAE paper 2007-01-0175 (2007). doi:10.4271/2007-01-0175.

[94] I. Glassman, Combustion, Academic Press, 1977, pp 52-56.

[95] N. Morgan, A. Smallbone, A. Bhave, M. Kraft, R. Cracknell, G. Kalghatgi, Combust. Flame, 157 (2010) $1122-1131$.

[96] J.C.G. Andrae, Fuel, 87 (2008) 2013-2022.

[97] M. Sarathy, G. Kukkadapu, M. Mehl, W. Wang, T. Javed, S. Park, M. Oehlschlaeger, A. Farooq, W.J.

Pitz, C.-J. Sung, Proc. Combust. Inst., 35, In press (2014).

[98] M.E. Baumgardner, S.M. Sarathy, A.J. Marchese, Energy Fuels, 27 (2013) 7778-7789.

[99] C.V. Naik, K. Puduppakkam, E. Meeks, L. Liang, SAE Technical Paper 2012-01-0149, 2012. doi:10.4271/2012-01-0149

[100] K. Schofield, Energy Fuels, 26 (2012) 5468-5480.

[101] D.A. Sheen, W. Tsang, Combust. Flame, 161 (2014) 1489-1498.

[102] M. Frenklach, Proc. Combust. Inst., 31 (2007) 125-140.

[103] Engine Combustion Network Experimental Data Archive. 〈http://www.ca.sandia.gov/ECN>.

[104] S. Kook, L.M. Pickett, Fuel, 93 (2012) 539-548.

[105] L.M. Pickett, D.L. Siebers, Int. J. Engine Res., 7 (2006) 103-130.

[106] S. Kook, L. Pickett, SAE Int. J. Fuels Lubr., 5 (2012) 647-664.

[107] S. Kook, L.M. Pickett, Proc. Combust. Inst., 33 (2011) 2911-2918.

[108] H. Bockhorn, A. D’Anna, A.F. Sarofim, H. Wang, eds., Proceedings of an International Workshop, Villa

Orlandi, Anacapri, Italy, May 13-16, (2009).

[109] H. Wang, Proc. Combust. Inst., 33 (2011) 41-67.

[110] ASTM D1322, ASTM International, 100 Barr Harbor Drive, PO Box C700, West Conshohocken, PA 19428-2959, United States., (2008).

[111] R.J. Watson, M.L. Botero, C.J. Ness, N.M. Morgan, M. Kraft, Fuel, 111 (2013) 120-130.

[112] M.T. Timko, Z. Yu, T.B. Onasch, H.W. Wong, R.C. Miake-Lye, A.J. Beyersdorf, B.E. Anderson, K.L.

Thornhill, E.L. Winstead, E. Corporan, M.J. DeWitt, C.D. Klingshirn, C. Wey, K. Tacina, D.S. Liscinsky, R. Howard, A. Bhargava, Energy Fuels, 24 (2010) 5883-5896.

[113] A.H. Lefebvre, Int. J. Heat and Mass Trans., 27 (1984) 1493-1510.

[114] H.F. Calcote, D.M. Manos, Combust. Flame, 49 (1983) 289-304. 
[115] R.J. Gill, D.B. Olson, Combust. Sci. Technol., 40 (1984) 307-315.

[116] A. Mensch, R.J. Santoro, T.A. Litzinger, S.Y. Lee, Combust. Flame, 157 (2010) 1097-1105.

[117] C.S. McEnally, D.M. Ciuparu, L.D. Pfefferle, Combust. Flame, 134 (2003) 339-353.

[118] C.S. McEnally, L.D. Pfefferle, Combust. Flame, 148 (2007) 210-222.

[119] C.S. McEnally, L.D. Pfefferle, Aromatic Hydrocarbon Growth Mechanisms in Flames: Insights from Sooting Tendency Measurements, in: A.D. H. Bockhorn, A. Sarofim and H. Wang (Ed.) Combustion Generated Fine Carbonaceous Particles, KIT Scientific Publishing (ISBN 978-3-86644-441-6), University of Utah, Department of Chemical Engineering, 2009.

[120] S. Dooley, S.H. Won, J. Heyne, T.I. Farouk, Y. Ju, F.L. Dryer, K. Kumar, X. Hui, C.-J. Sung, H. Wang, M.A. Oehlschlaeger, V. Iyer, S. Iyer, T.A. Litzinger, R.J. Santoro, T. Malewicki, K. Brezinsky, Combust. Flame, 159 (2012) 1444-1466.

[121] S. Dooley, S.H. Won, S. Jahangirian, Y. Ju, F.L. Dryer, H. Wang, M.A. Oehlschlaeger, Combust. Flame, 159 (2012) 3014-3020.

[122] F.M. Haas, A. Qin, F.L. Dryer, AIAA Propulsion and Energy Forum and Exposition 2014, Cleveland Medical Mart \& Convention Center, Cleveland OH, 28 - 30 July, 2014.. Paper JPC-1.

[123] F.L. Dryer, S.H. Won, S. Dooley, U.S. Pat. Pending - Provisional Patent No. 61/748,792, (2014).

[124] S.H. Won, S. Dooley, F.L. Dryer, Y. Ju, Combust. Flame, 159 (2012) 541-551.

[125] L. Li, P.B. Sunderland, Combust. Sci. Technol., 184 (2012) 829-841.

[126] L. Li, P.B. Sunderland, Fire Safety J., 61 (2013) 226-231.

[127] M.L. Botero, S. Mosbach, M. Kraft, Fuel, 126 (2014) 8-15.

[128] E.J. Barrientos, M. Lapuerta, A.L. Boehman, Combust. Flame, 160 (2013) 1484-1498.

[129] S. Yan, E.G. Eddings, A.B. Palotas, R.J. Pugmire, A.F. Sarofim, Energy Fuels, 19 (2005) 2408-2415.

[130] P. Pepiot-Desjardins, H. Pitsch, R. Malhotra, S.R. Kirby, A.L. Boehman, Combust. Flame, 154 (2008) 191-205.

[131] V. Iyer, S. Iyer, M. Linevsky, T. Litzinger, R.J. Santoro, S. Dooley, F.L. Dryer, C.J. Mordaunt, J. Prop. Power, 30 (2014) 1410-1418.

[132] B.D. Ditch, J.L. de Ris, T.K. Blanchat, M. Chaos, R.G. Bill Jr, S.B. Dorofeev, Combust. Flame, 160 (2013) 2964-2974.

[133] Z. Chen, J. Wen, B. Xu, S. Dembele, Fire Safety J., 64 (2014) 12-26.

[134] T.H. DeFries, R.V. Kastrup, D. Indritz, Ind. Eng. Chem. Res., 26 (1987) 188-193.

[135] S.W. Benson, Thermochemical Kinetics, 2nd ed., Wiley: New York, 1976.

[136] B. Diehl, G. Randel, Lipid Technol., 19 (2007) 258-260.

[137] R. Gieleciak, C. Fairbridge, in, Natural Resources Canada, Canmet ENERGY-Devon, 2013.

[138] D.J. Cookson, B.E. Smith, Energy Fuels, 4 (1990) 152-156.

[139] J.C. Edwards, P.J. Giammatteo, Chapter 10 in Process Analytical Technology, Katherine Bakeev (ed.), Blackwell Publishing, (2010).

[140] J.C. Edwards, Chapter 16 in Spectroscopic Analysis of Petroleum Products and Lubricants, ASTM International, (2011).

[141] M. Alnajjar, B. Cannella, H. Dettman, C. Fairbridge, J. Franz, T. Gallant, R. Gieleciak, D. Hager, C. Lay, S. Lewis, M. Ratcliff, S. Sluder, J. Storey, H. Yin, B. Zigler, CRC Report No. FACE-1, Coordinating Research Council, Alpharetta, Georgia. http://crcao.com/publications/advancedVehiclesFuelsLubricants/index.html., (2010).

[142] J.T. Bays, D.L. King, PNNL- 22472 National Technical Information Service, 5301 Shawnee Rd, Alexandria, VA 22312, (2013).

[143] B. Creton, C. Dartiguelongue, T. de Bruin, H. Toulhoat, Energy Fuels, 24 (2010) 5396-5403.

[144] D.A. Saldana, L. Starck, P. Mougin, B. Rousseau, L. Pidol, N. Jeuland, B. Creton, Energy Fuels, 25 (2011) 3900-3908.

[145] T. Sennott, C. Gotianun, R. Serres, M. Ziabasharhagh, J.H. Mack, R. Dibble, ASME 2013 Internal Combustion Engine Division Fall Technical Conference, Volume 2: Fuels; Numerical Simulation; Engine Design, Lubrication, and Applications, Dearborn, Michigan, USA, October 13-16 (2013).

[146] D.A. Saldana, L. Starck, P. Mougin, B. Rousseau, N. Ferrando, B. Creton, Energy Fuels, 26 (2012) 2416-2426.

[147] D.A. Saldana, L. Starck, P. Mougin, B. Rousseau, B. Creton, SAR QSAR Environ. Res., 24 (2013) 259277

[148] M. Hechinger, W. Marquardt, Comput. Chem. Eng., 34 (2010) 1507-1514. 
[149] D.A. Saldana, B. Creton, P. Mougin, N. Jeuland, B. Rousseau, L. Starck, Oil Gas Sci. Technol. - Rev. IFP Energies nouvelles, 68 (2013) 651-662.

[150] A.R. Katritzky, M. Kuanar, S. Slavov, C.D. Hall, M. Karelson, I. Kahn, D.A. Dobchev, Chem. Rev., 110 (2010) 5714-5789.

[151] P.T.M. Do, S. Crossley, M. Santikunaporn, D.E. Resasco, Catalytic Strategies for Improving Specific Fuel Properties, in: Catalysis: Volume 20, The Royal Society of Chemistry, 2007, pp. 33-64.

[152] R.C. Santana, P.T. Do, M. Santikunaporn, W.E. Alvarez, J.D. Taylor, E.L. Sughrue, D.E. Resasco, Fuel, 85 (2006) 643-656.

[153] S. Yang, Y. Ra, R.D. Reitz, B. VanDerWege, J. Yi, Int. J. Engine Res., 13 (2012) 370-384.

[154] A. Krishnasamy, R.D. Reitz, W. Willems, E. Kurtz, SAE Technical Paper 2013-01-1092, 2013, doi:10.4271/2013-01-1092.

[155] Y. Ra, R.D. Reitz, Int. J. Multiphas. Flow, 35 (2009) 101-117.

[156] B. Kerschgens, L. Cai, H. Pitsch, A. Janssen, M. Jakob, S. Pischinger, Int. J. Engine Res., (2014).

[157] P. Le Clercq, N. Doué, M. Rachner, M. Aigner, 47th AIAA Aerospace Sciences Meeting, 5-8 June, 2009, Orlando, FL, USA. Paper No. AIAA-2009-1188.

[158] B. Rauch, P. Le Clercq, M. Aigner, M. Rachner, C. Raffaela, P. Massoli, 49th AIAA Aerospace Sciences Meeting, 4 - 7 January, 2011 Orlando, Florida. Paper No AIAA 2011-790.

[159] P. Le Clercq, M. Di Domenico, M. Rachner, E. Ivanova, M. Aigner, 48th AIAA Aerospace Sciences Meeting, 4 - 7 January, 2010, Orlando, Florida. Paper AIAA 2010-613.

[160] H. Xu, Z. Yang, M. Chaos, F.L. Dryer, in, JANNAF 42nd Combustion Joint Sub-Committee Meeting Modeling and Data For Combustion Simulation, Boston Marriott Newton, Hanscom AF Base, Newton, MA, May 12-16, 2008., 2008.

[161] S. Dooley, S.H. Won, M. Chaos, J. Heyne, Y. Ju, F.L. Dryer, K. Kumar, C.-J. Sung, H. Wang, M.A. Oehlschlaeger, R.J. Santoro, T.A. Litzinger, Combust. Flame, 157 (2010) 2333-2339.

[162] D. Kim, J. Martz, A. Violi, Combust. Flame, 161 (2014) 1489-1498.

[163] A. Violi, S. Yan, E.G. Eddings, A.F. Sarofim, S. Granata, T. Faravelli, E. Ranzi, Combust. Sci. Technol., 174 (2002) 399-417.

[164] T. Edwards, L.Q. Maurice, J. Prop. Power, 17 (2001) 461-466.

[165] P. Dagaut, A. El Bakali, A. Ristori, Fuel, 85 (2006) 944-956.

[166] E.G. Eddings, S. Yan, W. Ciro, A.F. Sarofim, Combust. Sci. Technol., 177 (2005) 715-739.

[167] H.R. Zhang, E.G. Eddings, A.F. Sarofim, Envron. Sci. Technol., 42 (2008) 5615-5621.

[168] H.R. Zhang, E.G. Eddings, A.F. Sarofim, C.L. Mayne, Z. Yang, R.J. Pugmire, Selection of surrogates for jet fuels in Combustion Generated Fine Carbonaceous Particles, in: A.D. H. Bockhorn, A. Sarofim and H. Wang (Ed.) Combustion Generated Fine Carbonaceous Particles, KIT Scientific Publishing (ISBN 978-3-86644-441-6), University of Utah, Department of Chemical Engineering 2009, pp. 137-161.

[169] S. Jahangirian, C.S. McEnally, A. Gomez, Combust. Flame, 156 (2009) 1799-1809.

[170] W. Hentschel, K.-P. Schindler, O. Haahtela, SAE Technical Paper 941954, 1994. doi:10.4271/941954

[171] C. Wahl, EU FP5 G4RD-CT-00075 Final Report, DLR, German Aerospace Center, Institute of Combustion Technology, (2003).

[172] W. Tsang, J. Hudgens, T.C. Allison, D.R. Burgess, J.A. Manion, D. Matheu, Workshop on Combustion

Simulation Databases for Real Transportation Fuels, Workshop Report, NISTIR-7155, National Institute of Standards and Technology, Gaithersburg, MD, September, 4-5, (2003).

[173] J.T. Farrell, N.P. Cernansky, F.L. Dryer, D.G. Friend, C.A. Hergart, C.K. Law, R. McDavid, M. C.J., H. Pitsch, SAE Technical Paper 2007-01-0201, 2007. doi:10.4271/2007-01-0201.

[174] M. Colket, J.T. Edwards, S. Williams, N.P. Cernansky, D.L. Miller, F. Egolfopoulos, P. Lindstedt, K.

Seshadri, F.L. Dryer, C.K. Law, D.G. Friend, D.B. Lenhert, H. Pitsch, A. Sarofim, M. Smooke, W. Tsang, 45th AIAA Aerospace Sciences Meeting, Reno, NV, Jan 8-11. AIAA Paper 2007-0770, (2007).

[175] W.J. Pitz, C.J. Mueller, Prog. Energy Combust. Sci., 37 (2011) 330-350.

[176] N.A. Slavinskaya, A. Zizin, M. Aigner, J. Eng. Gas. Turb. Power, 132 (2010) 111501-111501.

[177] T.J. Bruno, L.S. Ott, T.M. Lovestead, M.L. Huber, Chem. Eng. Technol., 33 (2010) 363-376.

[178] T.J. Bruno, M.L. Huber, Energy Fuels, 24 (2010) 4277-4284.

[179] T.J. Bruno, B.L. Smith, Energy Fuels, 24 (2010) 4266-4276.

[180] F. Battin-Leclerc, E. Blurock, R. Bounaceur, R. Fournet, P.-A. Glaude, O. Herbinet, B. Sirjean, V. Warth, Chem. Soc. Rev., 40 (2011) 4762-4782.

[181] C.K. Westbrook, W.J. Pitz, O. Herbinet, H.J. Curran, E.J. Silke, Combust. Flame, 156 (2009) 181 -199. 
[182] S.M. Sarathy, C.K. Westbrook, M. Mehl, W.J. Pitz, C. Togbe, P. Dagaut, H. Wang, M.A. Oehlschlaeger, U. Niemann, K. Seshadri, P.S. Veloo, C. Ji, F.N. Egolfopoulos, T. Lu, Combust. Flame, 158 (2011) 2338-2357.

[183] S.M. Sarathy, T. Javed, F. Karsenty, A. Heufer, W. Wang, S. Park, A. Elwardany, A. Farooq, C.K. Westbrook, W.J. Pitz, M.A. Oehlschlaeger, G. Dayma, H.J. Curran, P. Dagaut, Combust. Flame, 161 (2014) 14441459 .

[184] M.E. MacDonald, W. Ren, Y. Zhu, D.F. Davidson, R.K. Hanson, Fuel, 103 (2013) 1060-1068.

[185] B.W. Weber, W.J. Pitz, M. Mehl, E.J. Silke, A.C. Davis, C.-J. Sung, Combust. Flame, 161 (2014) 19721983.

[186] A. Comandini, T. Dubois, S. Abid, N. Chaumeix, Energy Fuels, 28 (2013) 714-724.

[187] H. Nakamura, D. Darcy, M. Mehl, C.J. Tobin, W.K. Metcalfe, W.J. Pitz, C.K. Westbrook, H.J. Curran, Combust. Flame, 161 (2014) 49-64.

[188] D. Darcy, H. Nakamura, C.J. Tobin, M. Mehl, W.K. Metcalfe, W.J. Pitz, C.K. Westbrook, H.J. Curran, Combust. Flame, 161 (2014) 1460-1473.

[189] F. Battin-Leclerc, V. Warth, R. Bounaceur, B. Husson, O. Herbinet, P.-A. Glaude, Proc. Combust. Ins. 35, (2014) In Press. doi:10.1016/j.proci.2014.06.147.

[190] J.W. Allen, A.M. Scheer, C.W. Gao, S.S. Merchant, S.S. Vasu, O. Welz, J.D. Savee, D.L. Osborn, C. Lee, S. Vranckx, Z. Wang, F. Qi, R.X. Fernandes, W.H. Green, M.Z. Hadi, C.A. Taatjes, Combust. Flame, 161 (2014) 711-724.

[191] N. Hansen, S.S. Merchant, M.R. Harper, W.H. Green, Combust. Flame, 160 (2013) 2343-2351.

[192] F.L. Dryer, Science-Based Design of Fuel-Flexible Chemical Propulsion/Energy: Generation of Comprehensive Surrogate Kinetic Models and Validation Databases for Simulating Large Molecular Weight Hydrocarbon Fuels, AF Office of Scientific Research Final Report, Grant No. FA9550-07-1-0515, (2012).

[193] F.L. Dryer, I. Glassman, Combustion Chemistry of Chain Hydrocarbons, in: C.T. Bowman and J. Birkeland (Ed.) Alternative Hydrocarbon Fuels: Combustion and Chemical Kinetics, Progress in Astronautics and Aeronautics, 62, 1978, pp. 255.

[194] S. Japanwala, K.H. Chung, H.D. Dettman, M.R. Gray, Energy Fuels, 16 (2002) 477-484.

[195] S.H. Won, S. Dooley, P.S. Veloo, H. Wang, M.A. Oehlschlaeger, F.L. Dryer, Y. Ju, Combust. Flame, 161 (2014) 826-834.

[196] Dryer F.L., H. Won S, Y. Ju, ATJ and ATJ/JP-8 Blended Fuel Combustion Fundamentals, AFRL/RQTE FA8650-08-D-2806-0020, Sub Contract No. 13-8650-0020-51-C2, Universal Technologies Corporation, Dayton, OH 45432. Final Report, (2014).

[197] F.L. Dryer, S. Jahangirian, S. Dooley, S.H. Won, J. Heyne, V.R. Iyer, T.A. Litzinger, R.J. Santoro, Energy Fuels, 28 (2014) 3474-3485.

[198] P.S. Veloo, S. Jahangirian, F.L. Dryer, An Experimental and Kinetic Modeling Study of the Oxidation of C7-C14 n-alkanes, Work in Progress Poster, 34th International Symposium on Combustion, Warsaw University of Technology, Warsaw, Poland Jul 29-Aug 3. W2P-115, (2012).

[199] P.S. Veloo, S. Jahangirian, F.L. Dryer, An Experimental and Kinetic Modeling Study of the Oxidation of C7-C14 n-Alkanes, Spring Technical Meeting of the Central States Section of the Combustion Institute, Dayton OH, April 22-24, 2012. Pa[er No. 12S-41, (2012).

[200] P.S. Veloo, S. Jahangirian, F.L. Dryer, An Experimental and Kinetic Modeling Study of the Oxidation of C7-C14 n-Alkanes, Energy and Fuels, submitted, (2014).

[201] M.J. Murphy, J.D. Taylor, R.L. McCormick, National Renewable Energy Laboratory, Golden, CO, NREL/SR-540-36805, September, (2004).

[202] D. F.L., The Phenomenology of Modeling Combustion Chemistry", Part 1, Chapter 3 in: e. W. Bartok and A.F. Sarofim, J. (Ed.) Fossil Fuel Combustion - A Sourcebook, John Wiley and Sons Inc., NY., 1991.

[203] S. Dooley, D. F.L., W.S. H., J. Heyne, Y. Ju, P. Dievart, Energy Fuels, Submitted (2014).

[204] F.L. Dryer, S. Jahangirian, S. Dooley, S.H. Won, J.S. Heyne, V.R. Iyer, T.A. Litzinger, R.J. Santoro, Energy Fuels, 28 (2014) 3474-3485.

[205] K. Anand, Y. Ra, R.D. Reitz, B. Bunting, Energy Fuels, 25 (2011) 1474-1484.

[206] H. Wang, Q. Jiao, M. Yao, B. Yang, L. Qiu, R.D. Reitz, Int. J. Engine Res., 14 (2013) 434-451.

[207] S. Pierucci, E. Ranzi, Comput. Chem. Eng., 32 (2008) 805-826.

[208] E. Ranzi, A. Frassoldati, T. Faravelli, A. Cuoci, Energy Fuels, 23 (2009) 5287-5289.

[209] A. Stagni, A. Cuoci, A. Frassoldati, T. Faravelli, E. Ranzi, Ind. Eng. Chem. Res., 53 (2014) 9004-9016.

[210] E. Ranzi, A. Frassoldati, A. Stagni, M. Pelucchi, A. Cuoci, T. Faravelli, Int. J. Chem. Kinet., 46 (2014) $512-542$. 
[211] J. Li, Z. Zhao, A. Kazakov, F.L. Dryer, Int. J. Chem. Kinet., 36 (2004) 566-575.

[212] G.P. Smith, D.M. Golden, N.W. Frenklach, B. Moriarty, B. Eitneer, M. Goldenberg, C.T. Bowman, R.K. Hanson, S. Song, J. Gardiner, W.C., V.V. Lissianski, Z. Qin, GRI Mech 3.0 http://www.me.berkeley.edu/gri_mech/ [213] H.J. Curran, P. Gaffuri, W.J. Pitz, C.K. Westbrook, Combust. Flame, 114 (1998) 149-177.

[214] M. Mehl, W.J. Pitz, C.K. Westbrook, K. Yasunaga, C. Conroy, H.J. Curran, Proc. Combust. Inst., 33 (2011) 201-208.

[215] M.A. Oehlschlaeger, J. Steinberg, C.K. Westbrook, W.J. Pitz, Combust. Flame, 156 (2009) 2165-2172. [216] M. Chaos, Personal Communication, March 2014. 


\section{Figures}

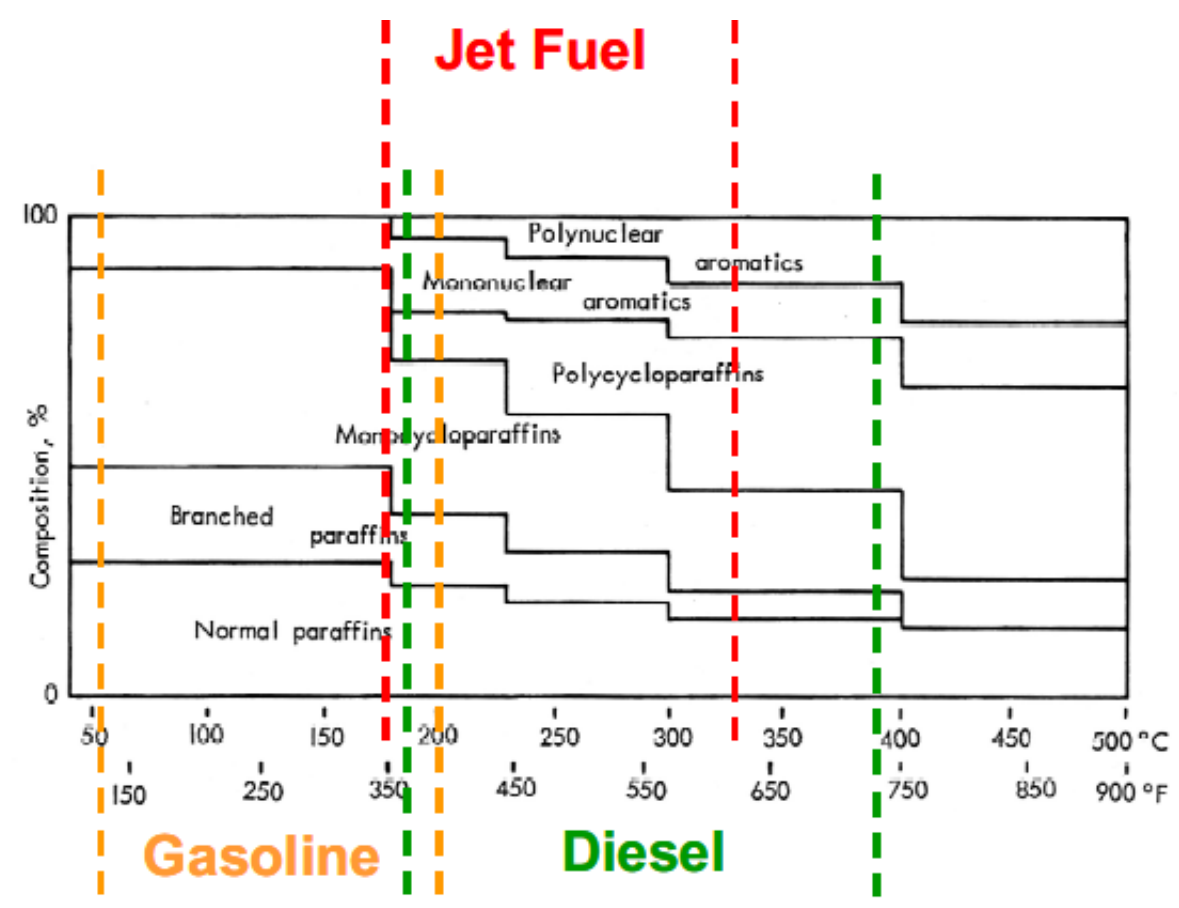

Figure 1: Typical distillation range and organic class distributions of species found in gasoline, diesel, and jet fuels. From Zhang et al. [168]. 


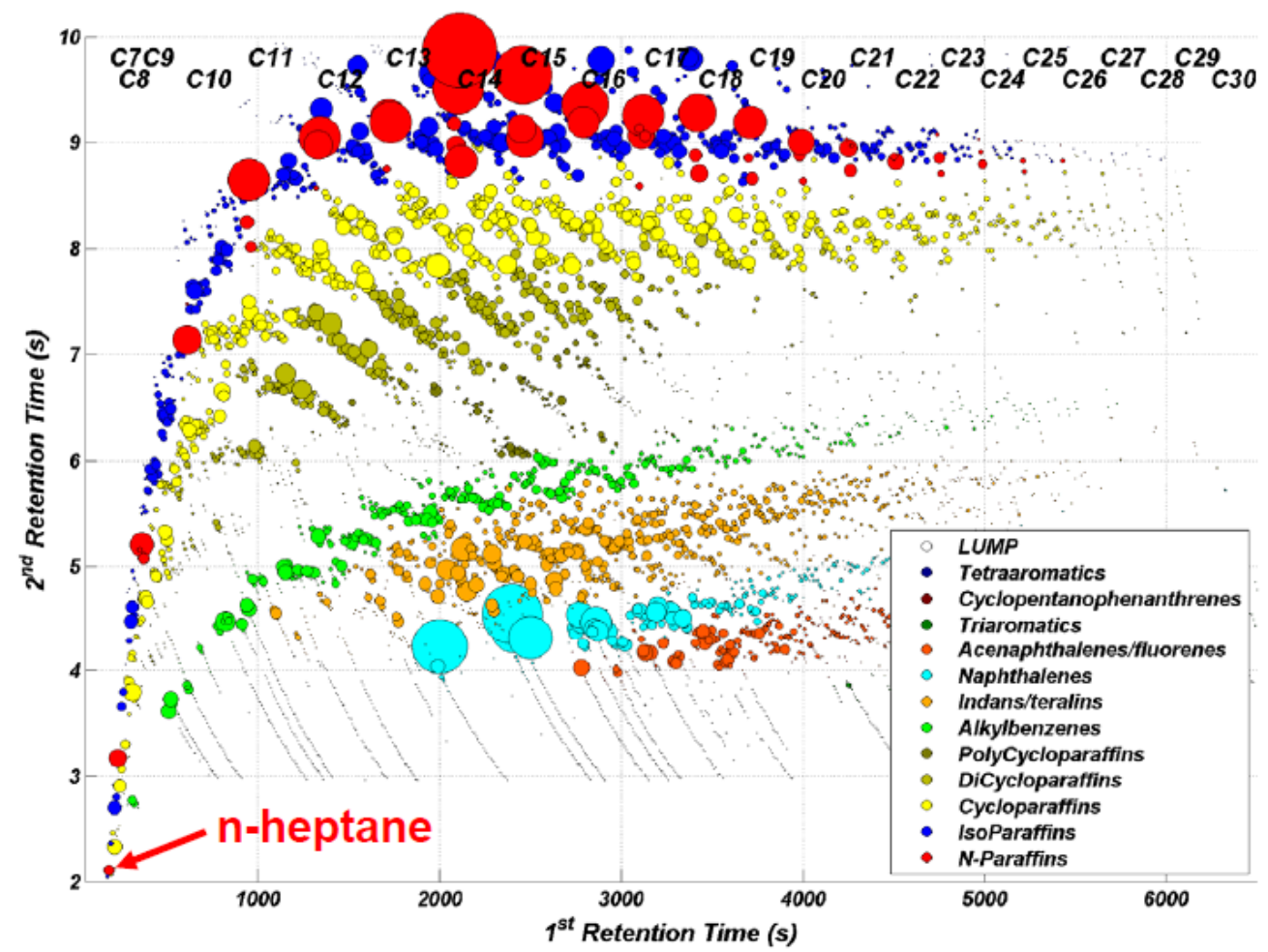

Figure 2: Two Dimensional GC analysis of a specific Diesel fuel sample. The diameter of each data point represents relative mass fraction of the specified molecular class and carbon number distribution in the fuel sample. From [137]. 


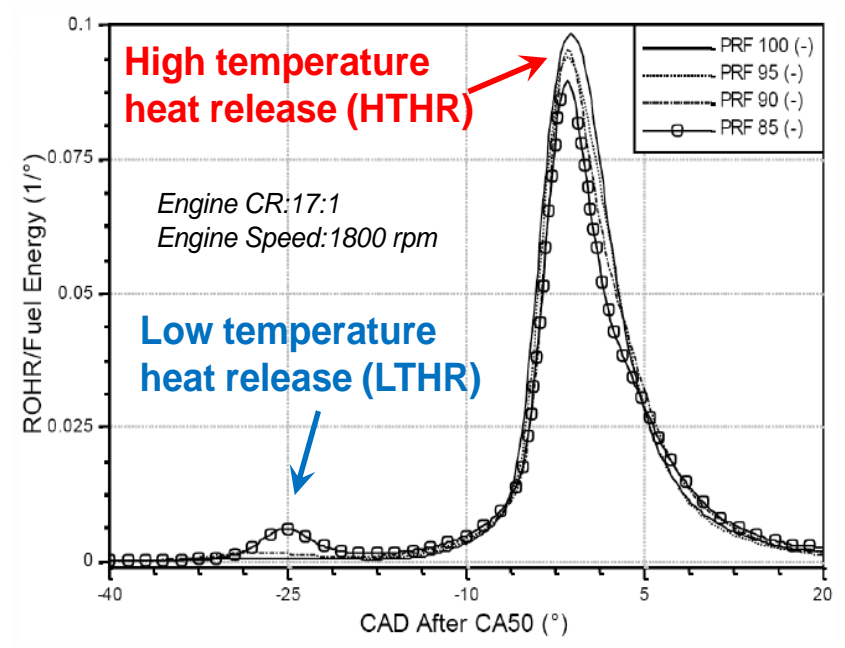

a)

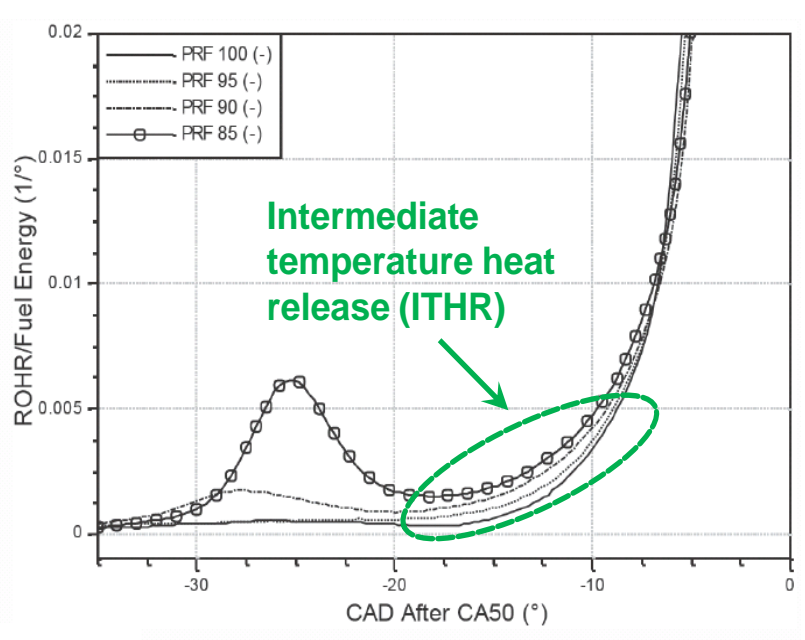

b)

Figure 3, Rate of heat release $(R O H R)$ as a function of engine crank angle (CAD) for various Primary Reference Fuel (PRF) mixtures. Engine operation at a compression ratio of 17:1, intake pressure, 1.4 bar. $1800 \mathrm{rpm}$, and fueling at phi=0.4, and 50\% heat release $(C A 50)$ adjusted to 6 degrees ATDC. Heat release profiles are scaled by total energy input. a) Profiles showing low temperature heat release $(L T H R)$ and high temperature heat release $(H T H R)$. b) Magnified image of $L T H R$ behavior. Note the transition between $L T H R$ and HTHR has a different Intermediate temperature heat release (ITHR) profile as a function of PRF mixture. From [83]. 


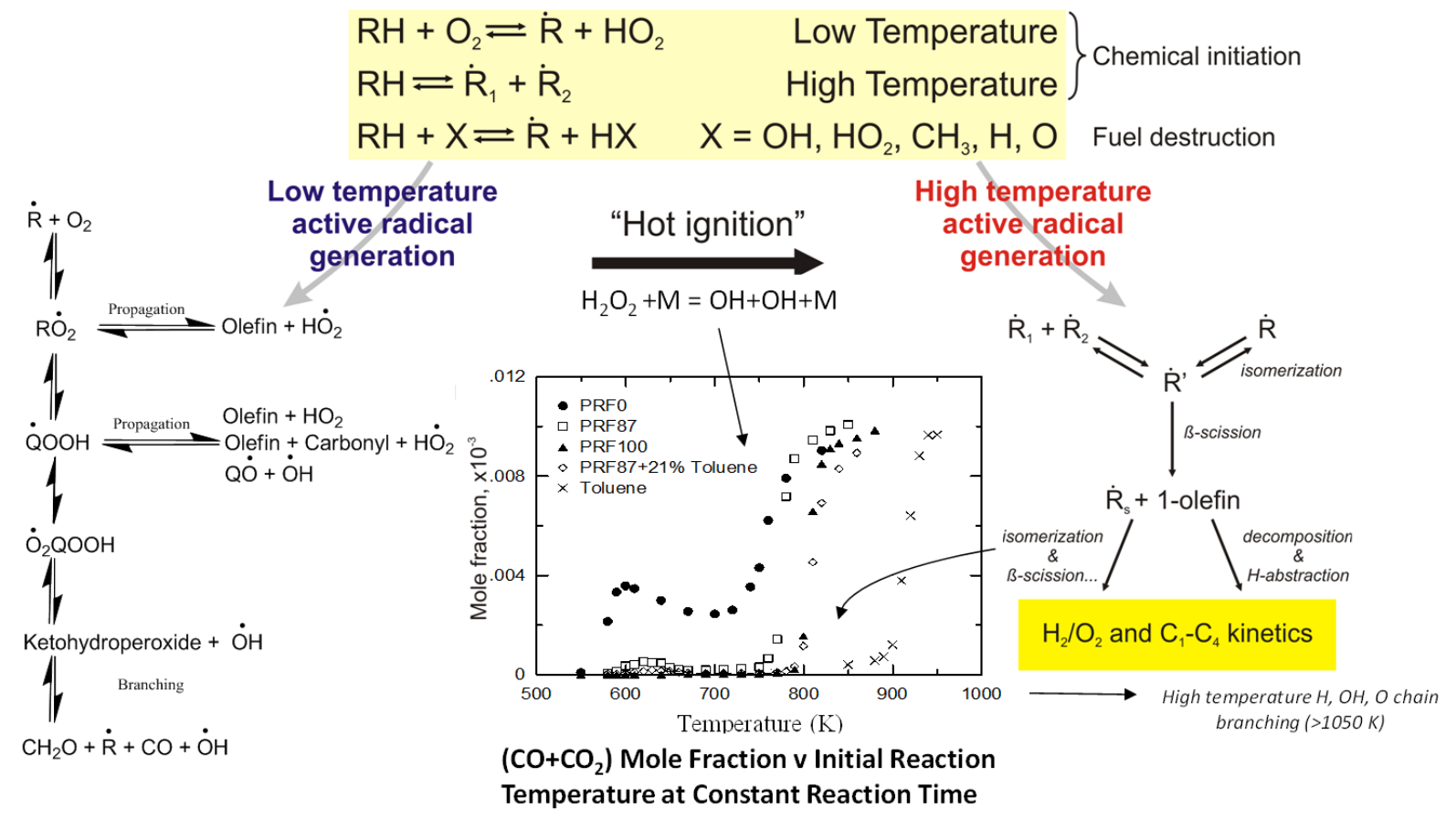

Figure 4: Mole Fraction $\left(\mathrm{CO}+\mathrm{CO}_{2}\right)$ kinetic reactivity for PRF, PRF $87+21 \%$ toluene, and pure toluene. Experiment: PrincetonVariable Pressure Flow Reactor. Mole fraction of species as a function of initial reaction temperature. Conditions: 12.5 atm pressure, reaction residence time $1800 \mathrm{~ms}, 670 \mathrm{ppm}$ carbon content (by vol) at $\phi=1$. The reactivity figure inset for various fuel mixtures is from [85]. 


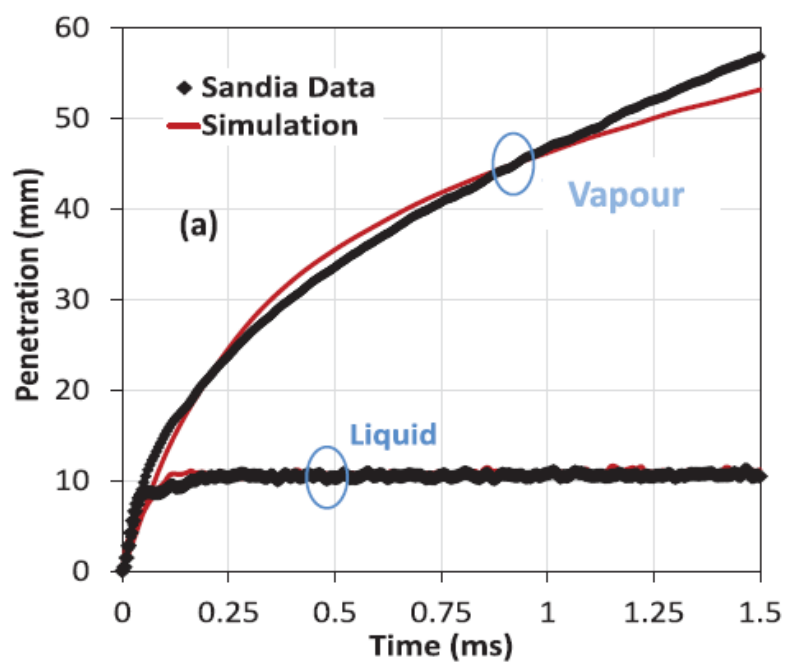

a)

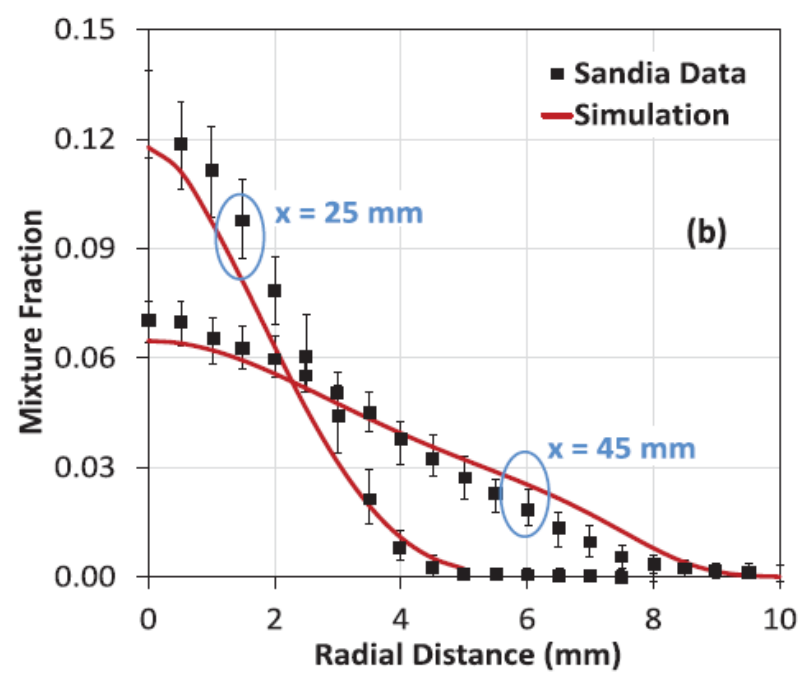

b)

Figure 5: Comparison of liquid and vapor penetration lengths for experiments with predictions for $\mathrm{n}$-dodecane at $900 \mathrm{~K}$ non reacting gas temperature and 71.5 bar pressure. a) liquid spray penetration and vapor penetration lengths as a function of time after start of injection (ASI). b) mixture fraction distribution $\mathrm{v}$ radial distance from spray centerline at two different axial positions at $1 \mathrm{~ms}$ ASI. Other pertinent parameters for the experiment are available in the paper. From [66]. 


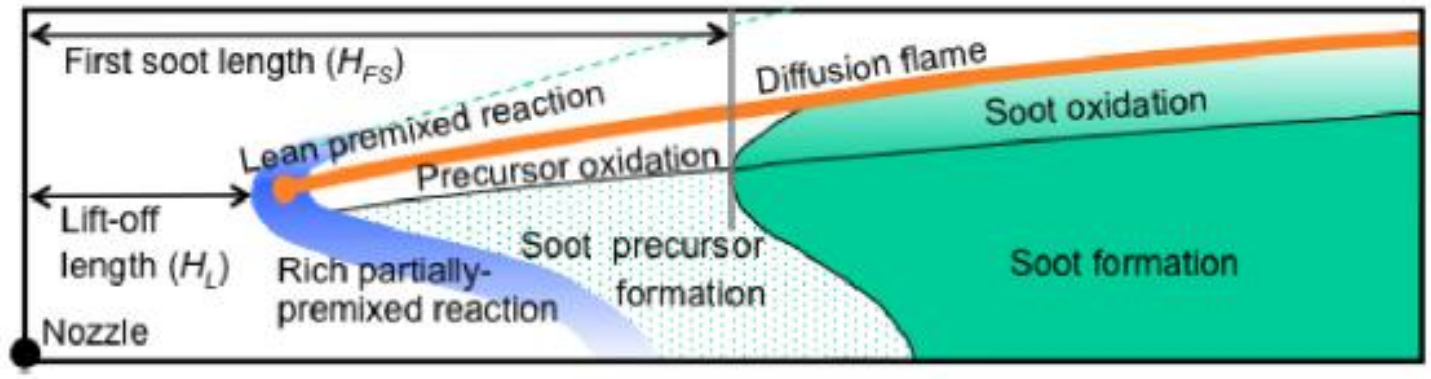

Figure 6: Conceptual sketch of flame properties and soot processes near the lift-off length in turbulent lifted jet flame adapted from the work of Pickett and Siebers [105]. The schematic shows one-half of an axisymmetric jet. 


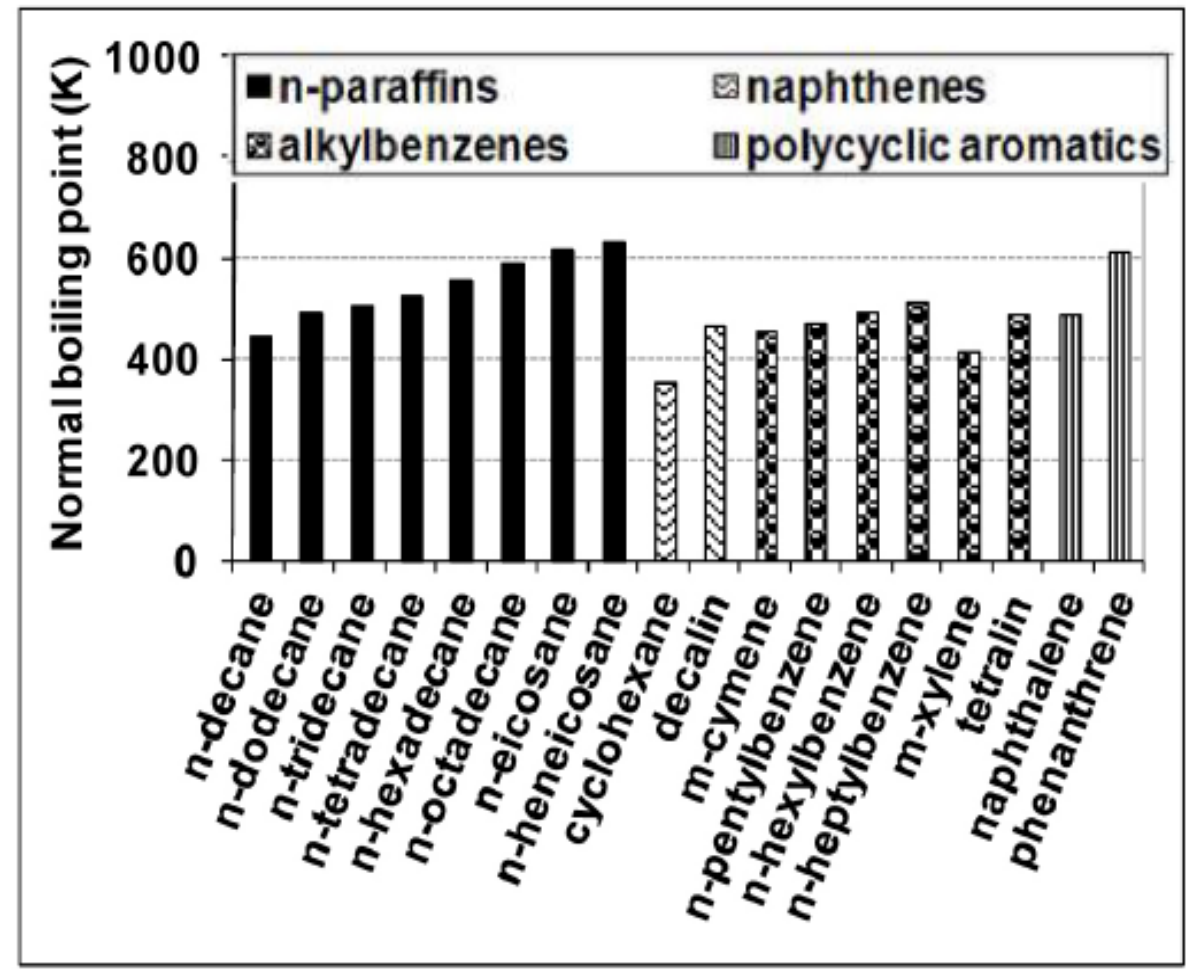

Figure 7: Surrogate species library used to emulate distillation and physical properties of diesel fuels. From [154]. 


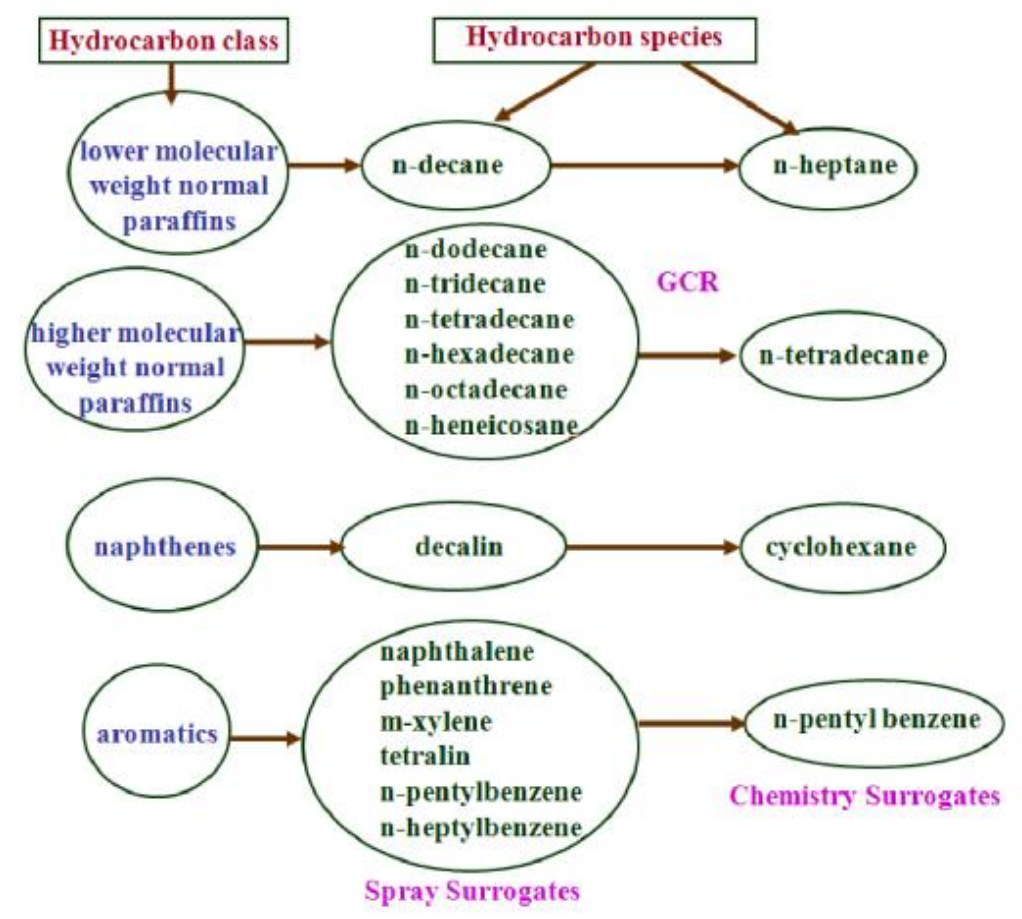

Figure 8: A molecular class approach to representing the chemical kinetics of multicomponent descriptions of fuel distillation and physical properties. From [154]. 


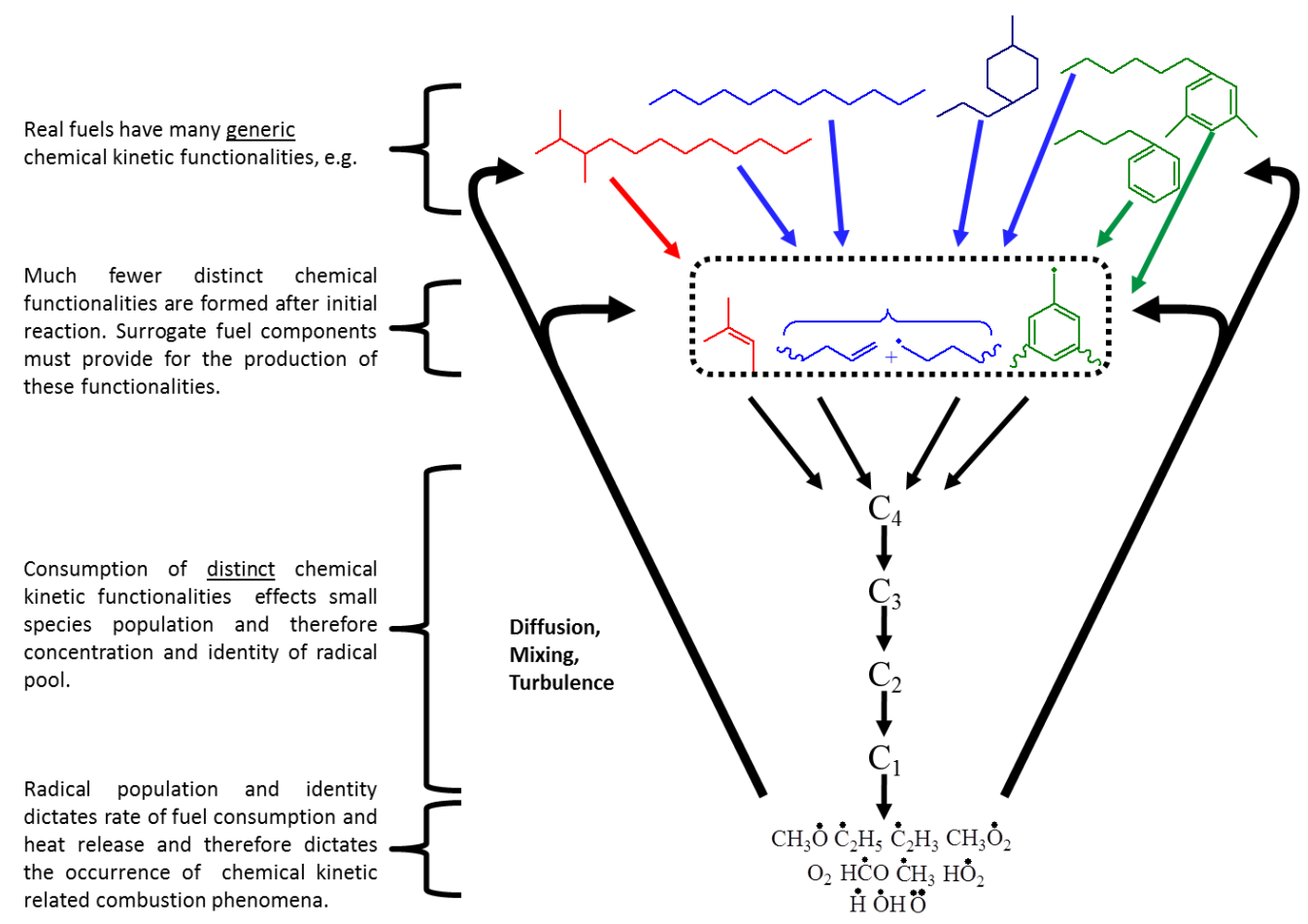

Figure 9: Schematic representation of the distinct chemical functionality concept for surrogate fuel formulations, adopted from Dooley et al. [120]. 

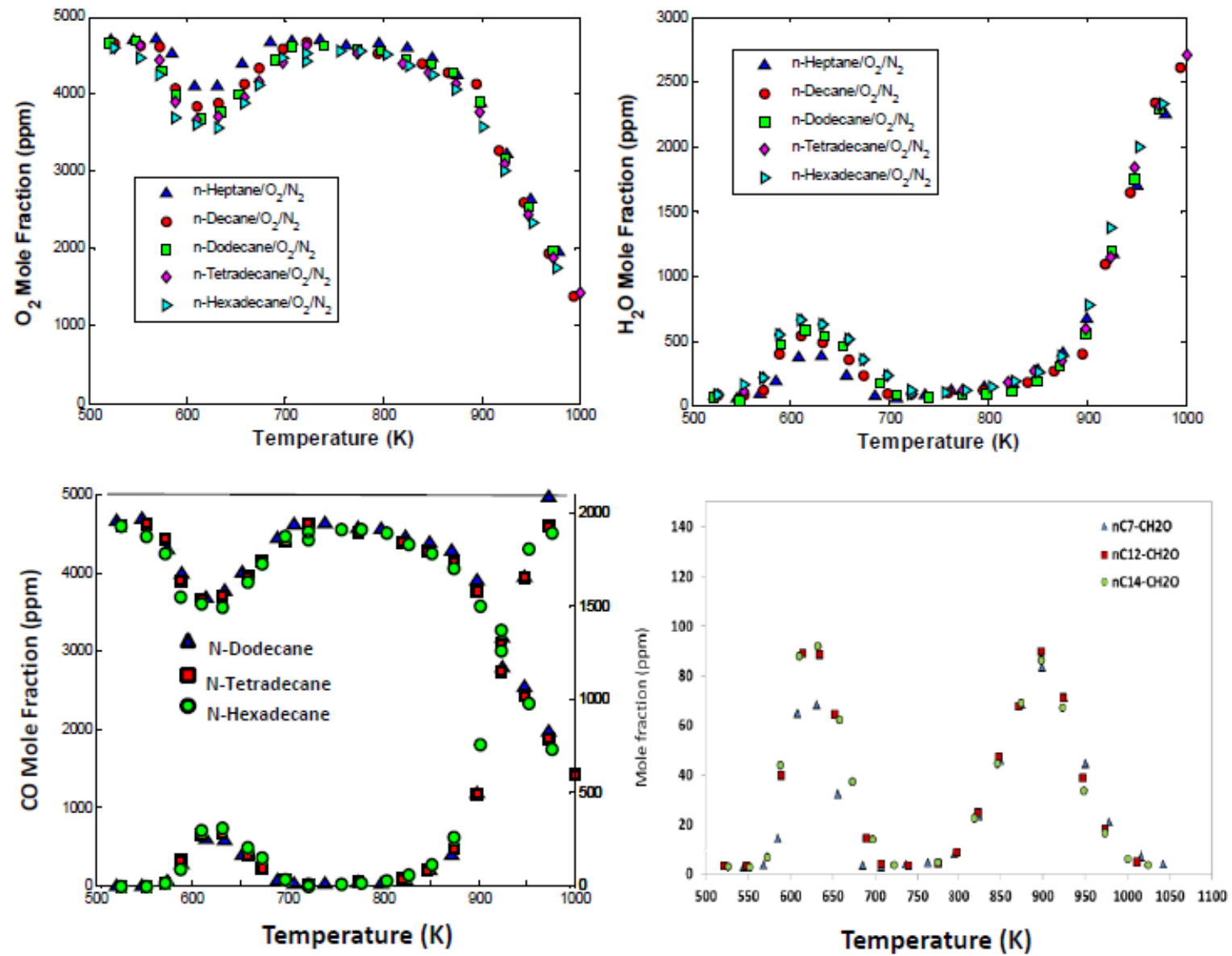

Figure 10: Princeton Variable Pressure flow reactor oxidation reactivity data for $n-\mathrm{C}_{7}-\mathrm{n}-\mathrm{C} 16$ alkanes as a function of initial reaction temperature. a) $\mathrm{O}_{2}$; b) $\mathrm{H}_{2} \mathrm{O}$; c) $\mathrm{CO}$; d) $\mathrm{CH}_{2} \mathrm{O}$. Conditions: $8 \mathrm{~atm}, 0.3 \mathrm{~mole} \%$ carbon, $\phi=1.0$, and $1.0 \mathrm{~s}$ residence time. From [198-200]. 


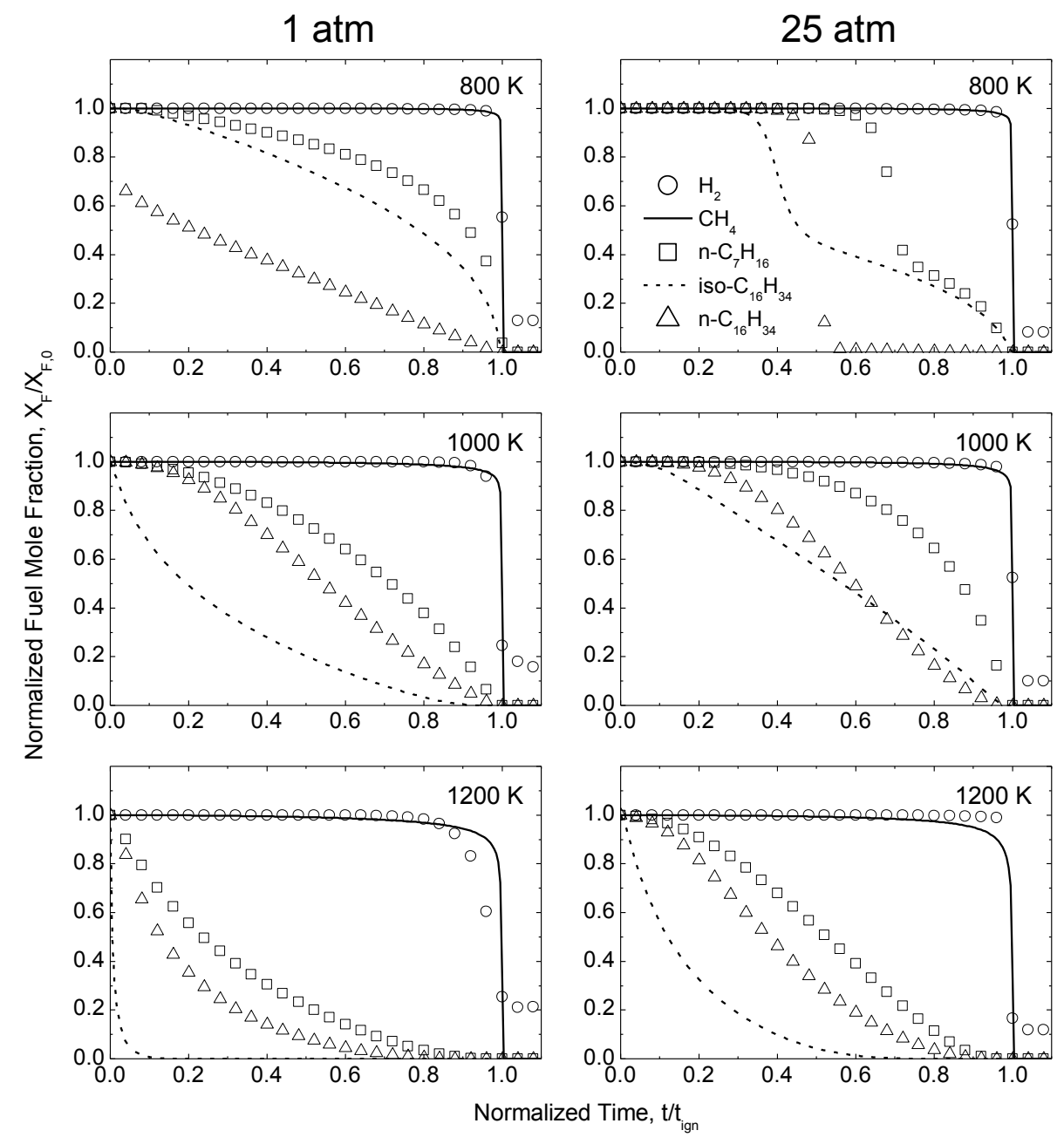

Figure 11: Fuel profiles during ignition of stoichiometric fuel/air mixtures at isochoric conditions for the given pressures and temperatures. The fuel mole fraction $\left(X_{\mathrm{F}}\right)$ has been normalized by the corresponding initial mole fraction $\left(X_{\mathrm{F}, 0}\right)$; profiles are plotted as a function of time normalized by the respective ignition delay time, $t_{\mathrm{ign}}$, for each condition. Kinetic Modeling sources: $\mathrm{H}_{2}$ [211] $\mathrm{CH}_{4}$ [212]; n-Heptane [213, 214]; n-Cetane [181]; iso-Cetane [215]. From [216]. 


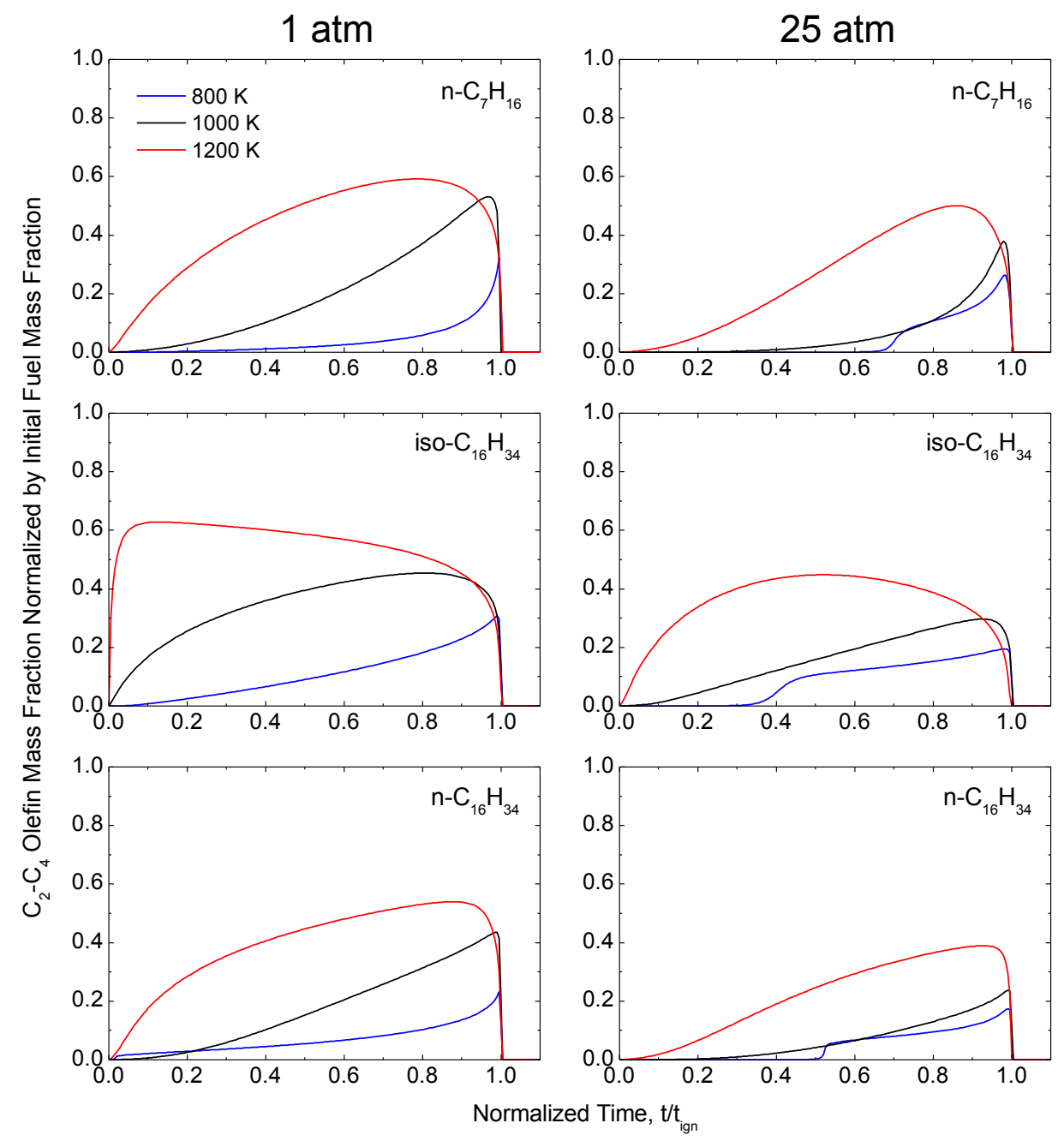

Figure 12: $\mathrm{C}_{2}-\mathrm{C}_{4}$ olefin production, expressed as the mass fraction of fuel consumed $\left[\Sigma Y_{\mathrm{C} n \mathrm{H} 2 n} /\left(Y_{\mathrm{F}, 0}-Y_{\mathrm{F}}\right)\right]$, during ignition of stoichiometric fuel/air mixtures. The profiles are plotted as a function of time normalized by the respective ignition delay time, $t_{\text {ign }}$, for each condition. Same conditions and modeling sources as in Figure 12. From [216]. 


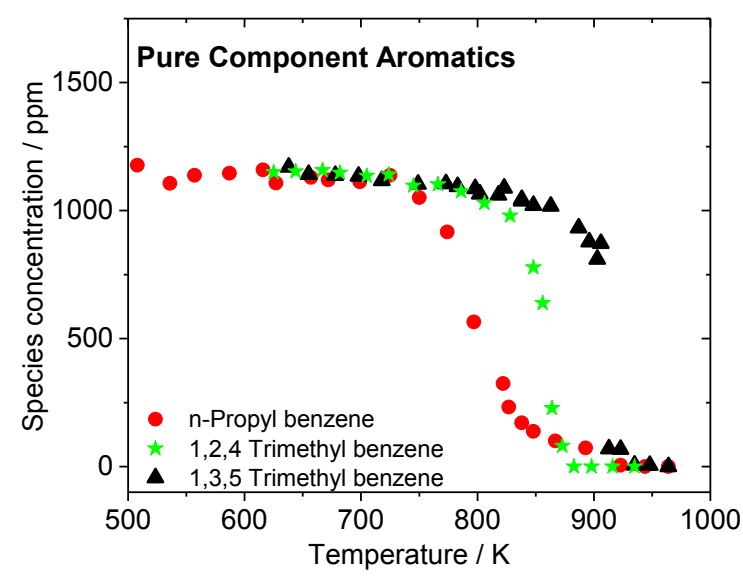

a)

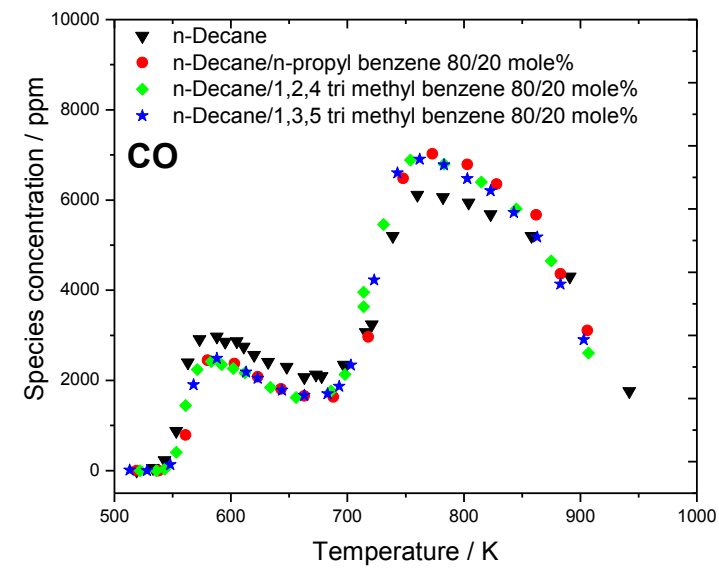

b)

Figure 13: VPFR reactivities of $\mathrm{C}_{9}$ aromatics, and mixtures of $80 \%$ n-decane $/ 20 \%$ molar percent aromatics. a) Comparison of pure n-propyl benzene, 1,2,4 tri methyl benzene, and 1,3,5 trimethyl benzene. b) Carbon monoxide reactivity profiles for $80 \%$ n-decane $/ 20 \%$ molar volume

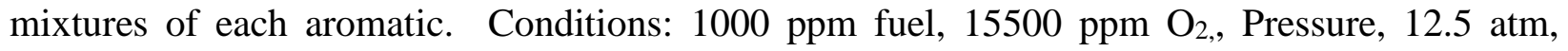
reaction residence time, $1.8 \mathrm{~s}$. 